Journal for ImmunoTherapy of Cancer

\title{
Targeting immunogenic cancer cell death by photodynamic therapy: past, present and future
}

\author{
Razan Alzeibak, ${ }^{1}$ Tatiana A. Mishchenko, ${ }^{1}$ Natalia Y. Shilyagina,${ }^{1}$ Irina V. Balalaeva, ${ }^{1}$ \\ Maria V. Vedunova, ${ }^{1}$ Dmitri V. Krysko (D) ${ }^{1,2,3}$
}

To cite: Alzeibak R, Mishchenko TA, Shilyagina NY, et al. Targeting immunogenic cancer cell death by photodynamic therapy: past, present and future. Journal for ImmunoTherapy of Cancer 2021;9:e001926. doi:10.1136/ jitc-2020-001926

- Additional material is published online only. To view, please visit the journal online (http://dx.doi.org/10.1136/jitc2020-001926).

RA and TAM are joint first authors.

MVV and DVK are joint senior authors.

Accepted 02 December 2020

Check for updates

(C) Author(s) (or their employer(s)) 2021. Re-use permitted under CC BY-NC. No commercial re-use. See rights and permissions. Published by BMJ.

${ }^{1}$ Institute of Biology and Biomedicine, Lobachevsky State University of Nizhny Novgorod, Nizhny Novgorod, Russian

Federation

${ }^{2}$ Cell Death Investigation and Therapy Laboratory (CDIT), Department of Human Structure and Repair, Ghent University,

Ghent, Belgium

${ }^{3}$ Cancer Research Institute Ghent, Ghent, Belgium

Correspondence to Professor Dmitri V. Krysko; dmitri.krysko@ugent.be

\section{ABSTRACT}

The past decade has witnessed major breakthroughs in cancer immunotherapy. This development has been largely motivated by cancer cell evasion of immunological control and consequent tumor resistance to conventional therapies. Immunogenic cell death (ICD) is considered one of the most promising ways to achieve total tumor cell elimination. It activates the T-cell adaptive immune response and results in the formation of long-term immunological memory. ICD can be triggered by many anticancer treatment modalities, including photodynamic therapy (PDT). In this review, we first discuss the role of PDT based on several classes of photosensitizers, including porphyrins and non-porphyrins, and critically evaluate their potential role in ICD induction. We emphasize the emerging trend of ICD induction by PDT in combination with nanotechnology, which represents third-generation photosensitizers and involves targeted induction of ICD by PDT. However, PDT also has some limitations, including the reduced efficiency of ICD induction in the hypoxic tumor microenvironment. Therefore, we critically evaluate strategies for overcoming this limitation, which is essential for increasing PDT efficiency. In the final part, we suggest several areas for future research for personalized cancer immunotherapy, including strategies based on oxygen-boosted PDT and nanoparticles. In conclusion, the insights from the last several years increasingly support the idea that PDT is a powerful strategy for inducing ICD in experimental cancer therapy. However, most studies have focused on mouse models, but it is necessary to validate this strategy in clinical settings, which will be a challenging research area in the future.

\section{INTRODUCTION}

The proper functioning of the immune system has a pivotal role in prevention of cancer initiation, progression and therapy. The role of the immune system in cancer therapy has been widely studied, and the modern paradigm of anticancer therapy has accepted the notion that interaction of dying/dead cancer cells with immune cells is a crucial factor determining cancer treatment efficiency. The Nobel Prize in Physiology or Medicine in 2018 reflects the significance of immunotherapy. The prize was awarded to
James P. Allison and T. Honjo for revealing the specific molecular players in immune surveillance and formulating a strategy for using checkpoint inhibitors as a potential cancer therapy. ${ }^{12}$

Over the past decade emerged the concept of immunogenic cell death (ICD), a cell death modality that stimulates innate and adaptive immune responses resulting in the generation of long-term immunological memory. ${ }^{3-5}$ The immunogenicity of cancer cell death is dictated by the antigenicity and adjuvanticity of dying cancer cells. ${ }^{36}$ The antigenicity of tumor cells is determined by the presence of tumor-associated antigens (TAA) and tumor neoantigens (TNA). However, they usually fail to drive efficient immunity in the absence of additional adjuvants required for the recruitment and activation of antigen-presenting cells (APC). ICD has an adjuvant-like effect mediated by the release of damage-associated molecular patterns (DAMPs). These molecules are normally retained within cells and integrated in their normal functioning, but once released outside the cells, they act as danger signals. ${ }^{78}$ DAMPs can be actively secreted, passively released extracellularly or exposed on the dying cell surface. It is believed that emitted DAMPs promote the recruitment and maturation of APCs (eg, dendritic cells) and thereby mediate presentation of TAA and TNA to effector CD8 T cells. The list of DAMPs is still expanding and includes calreticulin (CRT), heat shock proteins (HSPs) 70 and 90, high-mobility group box 1 (HMGB1), ATP, annexin A1, type I interferons (IFNs) and mitochondrial DNA. ${ }^{3} 910$ These molecules differ in origin, function, cell localization, release mechanism and stage of death at which they are released. ${ }^{11-13}$ The ability of cancer therapy to induce ICD is clinically important because ICD stimulates anticancer immune responses that are 
critical for the efficacy of the therapy and long-term anticancer immunity. ${ }^{14-17}$

Recently, much attention has been given to ICD, which can be induced by different stimuli and anticancer treatment modalities, including chemotherapy with anthracyclines and oxaliplatin, radiotherapy, UVC irradiation, oncolytic viruses and photodynamic therapy (PDT). ${ }^{4} 10151819$ The ICD induced by various stimuli can differ in the DAMPs' profile and has also been linked to different cell death modalities such as apoptosis, necroptosis $^{20-22}$ and ferroptosis. ${ }^{23}{ }^{24}$ In this review, we first discuss the role of PDT in the induction of ICD and then assess the advantages and disadvantages of PDT in the induction of ICD. Finally, we discuss possible strategies for enhancing the ICD-inducing potential of PDT-based anticancer therapies.

\section{MAIN PRINCIPLES OF PDT}

PDT of cancer involves the systemic, local or topical administration of a non-toxic, light-sensitive dye known as a photosensitizer (PS). After the PS accumulates selectively in the tumor, it is excited by illumination with visible light of appropriate wavelength. In the presence of molecular oxygen in cells and tissues, this leads to the generation of cytotoxic species and stimulation of signaling pathways, which consequently leads to cell death and tumor tissue destruction. ${ }^{25}$ PDT was first applied in the clinic in 1903 (box 1) and then it became widely used to treat several types of cancer. ${ }^{25-29}$ It is noteworthy that PDT is currently also used to treat some autoimmune ${ }^{30}$ and infectious diseases. ${ }^{31} 32$ Very recently, cetuximab saratolacan was approved by the Japanese government for the treatment of locally advanced or recurrent head and neck cancer. ${ }^{33}$ This is the first PS conjugated to an antibody; it consists of the water-soluble silicon-phthalocyanine derivative, IRDye700DX (IR700), conjugated to cetuximab. Cetuximab, which is approved by the FDA, targets the epidermal growth factor receptor, which is overexpressed in many types of cancer. In this treatment, after cetuximab saratolacan is injected intravenously, it attaches to head and neck cancer cells expressing high levels of EGFR. Subsequent illumination with red light $(690 \mathrm{~nm})$ as part of the PDT leads to induction of ICD in tumors and a potent anticancer immune response.

The photodynamic reaction during PDT is based on photophysical and photochemical processes (figure 1). After absorption of light (photons), the PS in its ground state is activated to the short-lived (nanoseconds) excited singlet state ${ }^{1} \mathrm{PS}^{*}$, after which it loses its energy by emitting light (fluorescence) or by internal conversion into heat. The excited singlet state ${ }^{1} \mathrm{PS}^{\bullet}$ may also undergo the process known as intersystem crossing to form the relatively long-lived (microseconds) excited triplet state ${ }^{3} \mathrm{PS}^{\circ}$. The excited triplet state ${ }^{3} \mathrm{PS}^{\bullet}$ can then undergo two kinds of reactions with surrounding molecules.

In the type I photochemical reaction, ${ }^{3} \mathrm{PS}$ reacts directly with a substrate, such as polyunsaturated fatty
Box 1 Historical background of photodynamic therapy (PDT): from fundamental studies to clinical practice

Discovery and development of PDT

A mechanism discovered in 1900 in Munich, Germany by Oscar Raab, who worked under the supervision of Professor Herman von Tappeiner, laid the basis of PDT. Studies on the effect of different dyes on protozoan viability helped him to notice that light irradiation of infusoria in the presence of acridine red dye leads to infusoria's death. Interestingly, the observed effect was more pronounced in comparison with light irradiation alone and with the dye action in the dark. Oscar Raab and Hermann von Tappeiner initially linked this phenomenon to light energy transfer to the dye, similar to photosynthesis. ${ }^{110} \mathrm{Dr} \mathrm{H}$. Tappeiner published research, ${ }^{111}$ in which he first suggested the possibility of using the photodynamic effect for medical purposes (the historical name of the mechanism is associated with light action on the dynamics-mobility —of cells; the term was introduced in 1907).

In 1907, Dr Jodlbauer and Dr Tappeiner proved that the development of photodynamic reactions requires the presence of oxygen in their environment. ${ }^{112}$

\section{PDT in clinical practice}

The use of the photodynamic effect in practice started only a few decades later. In 1948, Figge summarized a series of studies showing that exogenously injected porphyrins can selectively accumulate in murine tumors. ${ }^{113}$ In these years, suggestions emerged for the possibility of using porphyrins to detect malignancies in the body. In 1955, Schwartz obtained a purified mixture of hematoporphyrins known as hematoporphyrin derivative $(\mathrm{HpD})$, the first generation of photosensitizers. In 1978, Thomas Dougherty's team (Roswell Park Cancer Institute, Buffalo, New York, USA) used HpD to treat tumors of various localizations. ${ }^{114}$ Later, in 1980, Dougherty synthesized from HpD the drug Photofrin, a mixture of hematoporphyrin oligomers connected to each other by ester and complex ester linkages. At the same time, Photofrin analogs were obtained in different countries, including Photosan (Germany), Photogem (Russia), Hiporfin and Deuteporfin. ${ }^{115-117}$ Since the 1980s, there has been a rapid development of PDT, including the development of new drugs and capabilities for their application. Photosensitizers of different chemical nature are being developed, ${ }^{118}$ and areas of PDT application are expanding: anticancer therapy, acne ${ }^{119}$ antimicrobial therapy, ${ }^{32}$ psoriasis, ${ }^{120}$ atherosclerosis, ${ }^{121}$ herpes ${ }^{122}$ and age-related macular degeneration. ${ }^{123}$

acids in cell membrane lipids, and transfers an electron or a proton, leading to the formation of organic radicals (figure 1). These radicals may further react with cellular oxygen to produce reactive oxygen species (ROS) such as superoxide anion $\left(\mathrm{O}_{2}^{-\bullet}\right)$, hydroperoxide radical $\left(\mathrm{HOO}^{\circ}\right)$, peroxides $\left(\mathrm{H}_{2} \mathrm{O}_{2}, \mathrm{ROOH}\right)$ and hydroxyl radical $\left(\mathrm{HO}^{\circ}\right)$, and initiating free radical chain reactions. The hydroxyl radical, $\mathrm{HO}^{\circ}$, forms predominantly in the reaction of peroxides with $\mathrm{Fe}^{2+}$ (Fenton reaction). $\mathrm{HO}^{\bullet}$ is the most active oxygen radical, lives no more than hundreds of nanoseconds, and can oxidize almost any organic molecule. Alternatively, in the type II photochemical reaction, the triplet ${ }^{3} \mathrm{PS}{ }^{*}$ can undergo triplet-triplet energy transfer to molecular oxygen (triplet in the ground state) to form excited-state singlet oxygen $\left({ }^{1} \mathrm{O}_{2}\right)$, an extremely strong oxidizing agent with a lifetime in biologic media from a few to hundreds of nanoseconds (figure 1). Type I and 

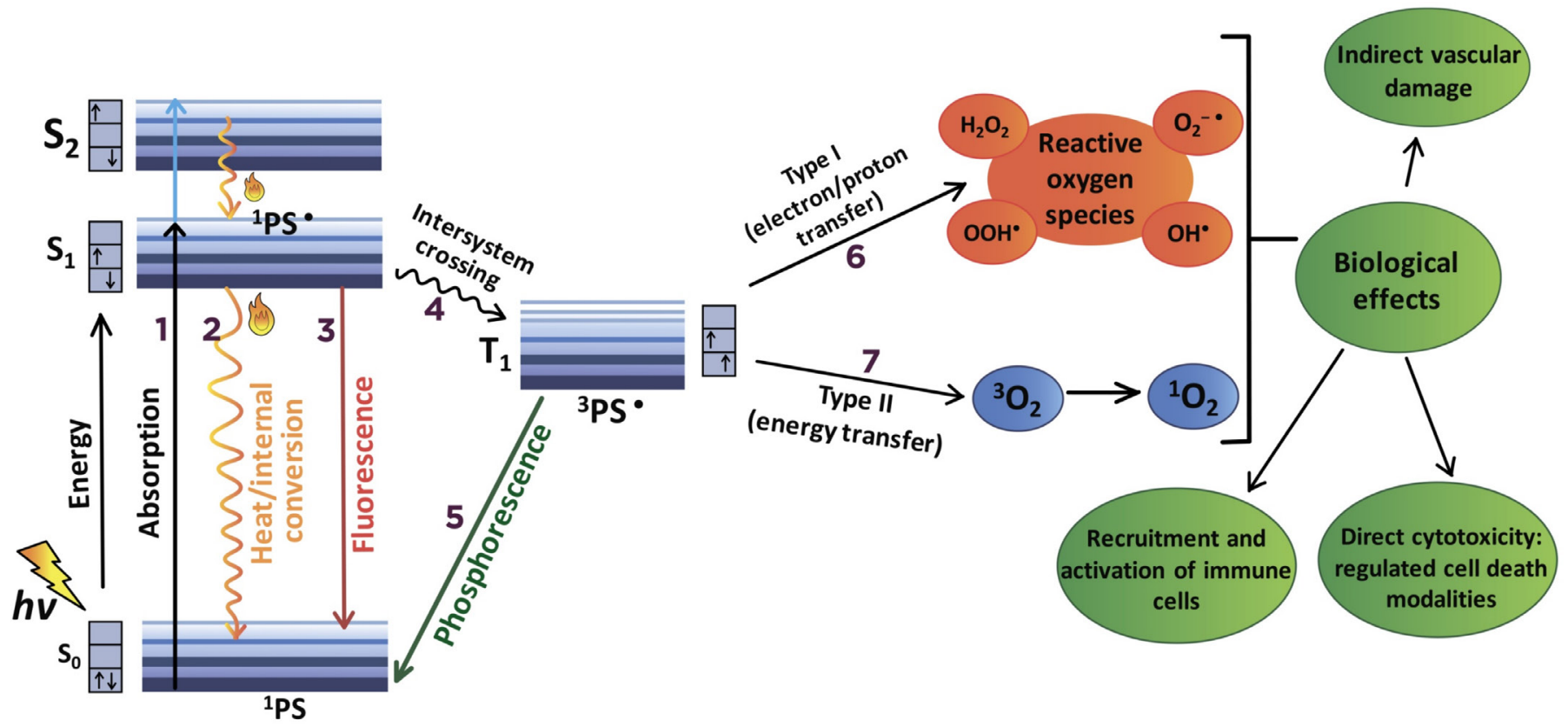

Figure 1 Mechanisms of photodynamic reaction during photodynamic therapy (PDT). (1) Following the absorption of photons (hv), one of the electrons of the photosensitizer (PS) is boosted into a high-energy orbital $\left(\mathrm{S}_{1}\right.$ or $\left.\mathrm{S}_{2}\right)$ and activated to the short-lived (nanoseconds) excited singlet state ( $\left.{ }^{1} \mathrm{PS} \mathrm{S}^{\circ}\right) .{ }^{1} \mathrm{PS} \mathrm{S}^{\bullet}$ can lose its energy by internal conversion into heat (2) or by emitting light (fluorescence) (3). Alternatively, ${ }^{1} \mathrm{PS}{ }^{\bullet}$ transforms into a relatively long-lived (microseconds) excited triplet state $\left({ }^{3} \mathrm{PS} \mathrm{S}^{\circ}\right.$ ) via an intersystem crossing process (4). ${ }^{3} \mathrm{PS}{ }^{\bullet}$ moves directly from a triplet to a singlet state $\left({ }^{1} \mathrm{PS}\right)$ by emission of light (phosphorescence) (5) or undergoes two kinds of reactions with surrounding molecules. In the type I photochemical reaction (6), ${ }^{3} \mathrm{PS}{ }^{\bullet}$ reacts directly with a substrate (eg, polyunsaturated fatty acids in cell membrane lipids) and transfers an electron or a proton, forming organic radicals. These radicals may further react with cellular oxygen to produce reactive oxygen species (ROS), such as superoxide anion $\left(\mathrm{O}_{2}^{-*}\right)$, hydroperoxide radical $(\mathrm{HOO})$, peroxides $\left(\mathrm{H}_{2} \mathrm{O}_{2}, \mathrm{ROOH}\right)$ and hydroxyl radical $(\mathrm{HO})$, as well initiate free radical chain reactions. In the type II photochemical reaction (7), the triplet ${ }^{3} \mathrm{PS}^{\circ}$ can undergo triplet- $^{2}$ triplet energy transfer to molecular oxygen (triplet in the ground state) to form excited-state singlet oxygen $\left({ }^{1} \mathrm{O}_{2}\right)$. Type I and type II photochemical reactions can be simultaneous, and the ratio between them depends mainly on the type of PS used, the concentrations of substrate and the availability of oxygen. As a result of the photodynamic reaction, various molecular mechanisms are activated, leading to different cell death modalities, recruitment and activation of immune cells and vascular damage.

type II photochemical reactions can occur simultaneously, and the ratio between them depends mainly on the PS type, substrate concentrations and oxygen availability. However, for example, when using tetrapyrrolic PS in a cellular environment, type II photochemical reactions prevail, and ${ }^{1} \mathrm{O}_{2}$ is regarded as the most important ROS in PDT-mediated cytotoxicity. The primary products of the interaction of ${ }^{1} \mathrm{O}_{2}$ with biological molecules (including lipids, proteins and nucleic acids) are hydroperoxides and cyclic endoperoxides, the decomposition of which, as in type I photodynamic reactions, initiates chain reactions of free radical peroxidation.

PSs can be divided according to chemical structure into non-porphyrin and porphyrin (or tetrapyrrole) compounds. The most common non-porphyrin PSs are based on phenothiazine dyes (analogs of methylene blue and toluidine blue), cyanines such as merocyanine 540 and polycyclic aromatic compounds, including hypericin and hypocrellin. PSs with a tetrapyrrole structure are more common. The first clinically approved PSs are hematoporphyrins (HpD, eg, Photofrin) (box 1), which are still being used in the clinic, for example, for treatment of cancer of the cervix, ${ }^{34}$ esophagus, ${ }^{35}$ colorectal cancer $^{36}$ and oral squamous cell carcinomas (SCC). ${ }^{37}$ Efforts to reduce the skin toxicity of PSs optimize their optical and physico-chemical properties and improve their selective accumulation in tumors led to the production of numerous second-generation photoactive dyes. Active substances that have been clinically approved or are being preclinically tested as second-generation PSs are from the groups of texafirins (Lutrin), phenylporphyrins (m-THPP), chlorins (NPe6, Foscan, Verteporfin, Radachlorin, Photodithazine), bacteriochlorins (Tookad) and porphyrazines (Photosens, Photocyanine, Pc4). Besides this, 5-aminolevulinic acid and its derivatives, which are low-molecular-weight prodrugs, are precursors of endogenous protoporphyrin XI in the heme biosynthetic pathway. To further improve the pharmacokinetics of PSs and thereby reduce their systemic side effects, so-called third-generation PSs are being proposed by various research groups. The main idea of third-generation PSs is based on combining a photoactive chromophore with a targeting moiety or vehicle for directed delivery to cancer cells. In recent years, nanotechnology has been used for this purpose, including polymeric nanoparticles, micelles, nanostructured lipid 
Box 2 Role of the photodynamic therapy (PDT) in the modulation of anticancer immunity

Several studies revealed that PDT effectively modulates both innate and adaptive immunity. Local injuries and oxidative stress in the tumor tissue induced by PDT activate an acute inflammatory process necessary to remove tissue residues and restore homeostasis (direct pathway). On the other hand, immunogenic cell death (ICD) induced by PDT leads to activation of antitumor immunity through danger signaling mechanisms caused by activation of damage-associated molecular patterns (DAMPs), which stimulate innate immunity, resulting in activation of adaptive immune responses (indirect pathway). ${ }^{124}$

The participation of the immune system in the development of the organism's response to photodynamic effects (direct pathway) was first mentioned in a paper by Yamamoto et al in 1991, who described the activation of macrophages (mediated by Fc-receptors) due to lipid peroxidation of lymphocyte membranes under the action of reactive oxygen species generated by photodynamic reactions. ${ }^{125}$ In 1993, Agarwal et al showed that PDT causes rapid and massive release of proinflammatory mediators from the membranes of tumor cells, damaged endothelial cells and tumor stroma cells. ${ }^{126127}$ In 1996, Korbelik revealed the induction of inflammatory mediators during PDT, such as arachidonic acid, cytokines, histamine and the complement system. ${ }^{128}$

In the same period, the works of Gollnick et al and Nseyo et al were the first to mention that PDT-treated cells secrete a number of cytokines, including tumor necrosis factor, interleukin (IL)-1 $\beta$ and IL-6, which participate in the recruitment of neutrophils and other myeloid cells. ${ }^{129} 130$ A few years later, Gollnick et al demonstrated that tumor cell lysates obtained after PDT can activate dendritic cells and induce an antitumor immune response (indirect pathway). ${ }^{131}$ A decade later, in 2012, the team led by P Agostinis used a 'gold standard' model of immunocompetent mice vaccinated with PDT-treated cancer cells to demonstrate for the first time the immunogenic nature of PDT-induced tumor cell death. $^{43}$

carriers, liposomes and metal nanoparticles. In addition, targeted PS delivery is also being developed by using the technology for dendrimer preparation and conjugation of PSs with biomolecules, including sugars actively captured by tumor cells or proteins effectively binding to receptors that are hyperexpressed on the tumor cell surface. $^{38} 39$

The radical ${ }^{1} \mathrm{O}_{2}$, the photochemical production of which underlies the photodynamic effect of almost all PSs, has a short lifetime. Therefore, it is important that PS localization in tumor tissue occurs between PS administration and irradiation (drug-to-light interval). The production of ROS induced by PDT leads to tumor destruction by various mechanisms, depending on the localization of the particular PS. PDT influences the tumor vasculature, causing shutdown of vessels and consequently depriving the tumor of oxygen and nutrients. ${ }^{40}$ Equally important is the rapid recruitment and activation of immune cells, which leads to tumor elimination and long-term tumor control $^{41}{ }^{42}$ (box 2). Importantly, PDT can also directly induce ICD of tumor cells by irreversible light-driven damage, which will be discussed further in this review (figure 2).

\section{PS FEATURES: SUBCELLULAR LOCALIZATION AND DOSE}

Depending on their chemical properties, PSs can accumulate and initiate their damage in different cellular compartments. The main sites of PS localization are mitochondria, lysosomes, the endoplasmic reticulum (ER), Golgi apparatus, plasma membrane or their combinations. As localization plays an important role in determining whether the cell death will be immunogenic, characterization of new PSs should include analysis of their subcellular localization sites. It has been shown that one of the prerequisites of ICD is ROS production induced by ER stress, with subsequent exposure of one of the key DAMPs, CRT and activation of the host immune system against cancer. ${ }^{19}{ }^{43}$ Therefore, from the point of view of PDT-induced ICD, it is logical to assume that direct targeting of PSs into the ER will be an effective strategy for cancer eradication. For instance, some studies have demonstrated that hypericin directly accumulates in the ER, and on PDT, it leads to the production of high levels of ROS and subsequent formation of strong immune responses. ${ }^{43} 44$ However, not all PSs accumulate in the ER. For a PS to accumulate in the ER, it must have hydrophobic or amphiphilic properties, and in the latter case, it also depends on the charge of the PS molecule. Hydrophilic PSs localize primarily in endosomes/lysosomes and are then redistributed in the cytoplasm. If the PS is delivered directly into the ER, both PDT efficiency and immunogenic effects increase. ${ }^{43}$ Several studies implemented this strategy by double-targeting the ER to trigger robust ER stress. For instance, a nanosystem for synchronous ER-targeting PDT immunotherapy has been developed. The first part of the system ensures delivery of the PS indocyanine green by conjugating it with hollow gold nanospheres and FAL peptides acting as targets for the ER. The second part consists of FAL-modified liposomes linked to hemoglobin as an adjuvant oxygen supply. Although indocyanine green localizes mainly in the cytoplasm, its targeted delivery into the ER in combination with enhancement of oxygen availability induces robust ROS-based ER stress followed by CRT exposure, DC maturation $\left(\mathrm{CD} 11 \mathrm{c}^{+} \mathrm{CD} 80^{+} \mathrm{CD} 86^{+}\right)$, stimulation of $\mathrm{CD}^{+}$and $\mathrm{CD}^{+} \mathrm{T}$ cell proliferation and production of cytotoxic cytokines (tumor necrosis factor (TNF)- $\alpha$, IFN- $\gamma$ ) in CT26 and B16 tumor models. ${ }^{45}$ The ER involvement in the development of an immunogenic response was shown for photodithazine-based PDT against murine glioma GL261 and murine fibrosarcoma MCA205 cells. ${ }^{46}$ These findings indicate that redirecting the PS to localize in the ER promotes effective PDT-induced cancer cell death, followed by development of an adaptive antitumor immune response.

On the other hand, localization of the PS in other cellular compartments may also have immunogenic properties when used in PDT. In this regard, it has been shown that while photosens is localize mainly in lysosomes, its immunogenicity in PDT has been demonstrated. This immunogenicity is characterized by DAMPs emission (CRT, HMGB1 and ATP), DC maturation and effective 


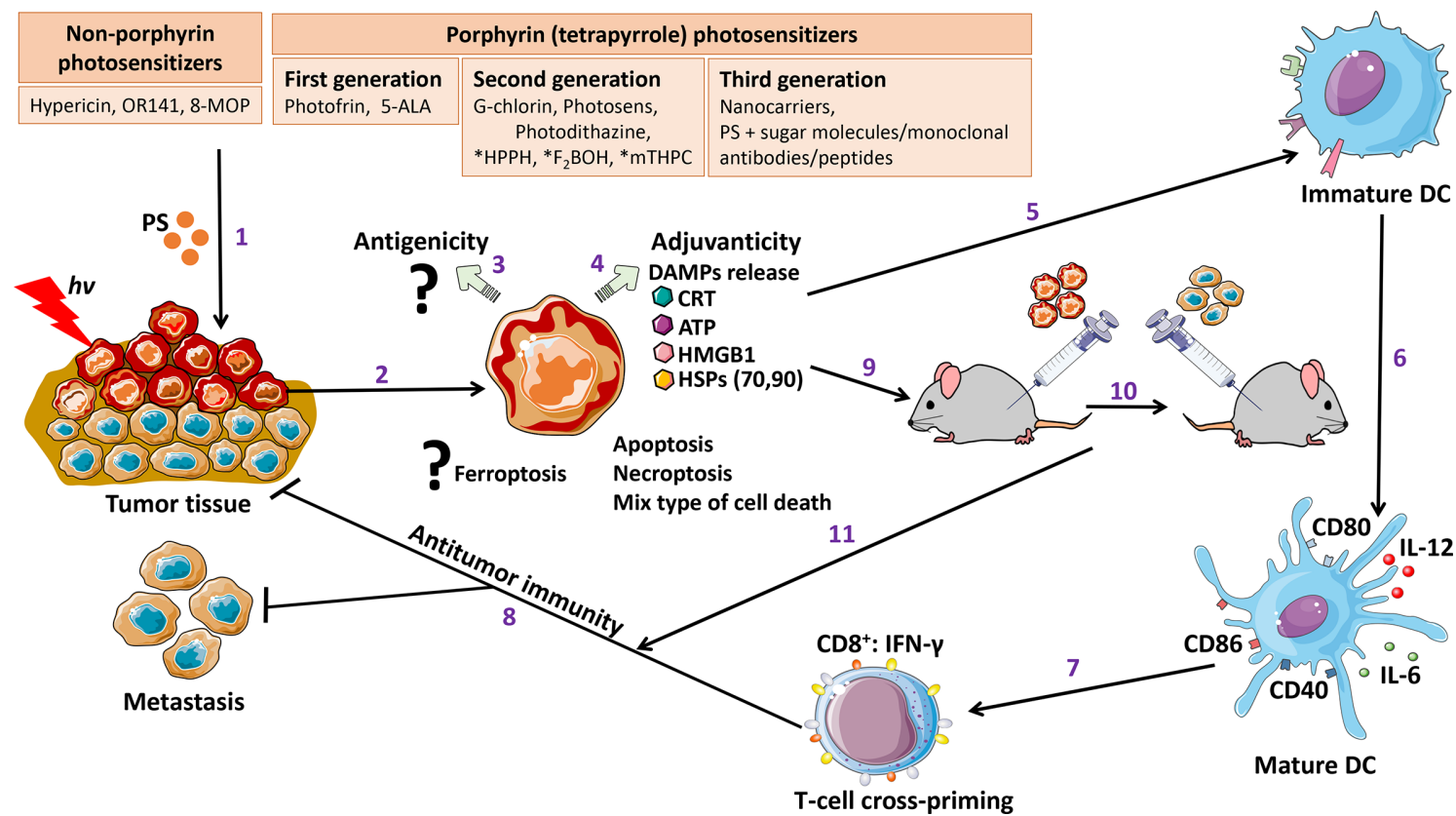

Figure 2 Photodynamic therapy (PDT)-induced immunogenic dell death at a glance. Photosensitizers (PSs) used in PDT have various chemical structures and can be divided into non-porphyrin and porphyrin (or tetrapyrrole) compounds. It has been experimentally proven that after accumulation in tumor cells and excitation by light of appropriate wavelength (hv), some PSs in each group of PSs can induce immunogenic cell death (ICD) (1). ICD refers to an immunological feature of cell death and is observed in immunogenic apoptosis and immunogenic necroptosis, as well as in mixed cell death types (2). The role of PDT in the induction of ferroptosis ${ }^{132} 133$ in cancer cells needs to be further clarified ${ }^{134}$. Importantly, only a fraction of cancer cells can be reached by light during PDT because light can penetrate only to a limited depth. ICD stimulates innate and adaptive immune responses, resulting in long-term immunological memory. Of note, the immunogenicity of ICD is mediated by the antigenicity (3) and adjuvanticity (4) of dying/dead cancer cells. The antigenicity of tumor cells is determined by the presence of tumorassociated antigens and tumor neoantigens (3). However, tumor-associated antigens usually fail to drive efficient immunity in the absence of additional adjuvants required to recruit and activate antigen-presenting cells. It is currently not known how PDT in combination with the above-mentioned PSs can modulate the antigenicity of dying cancer cells. The adjuvanticity of ICD resides in the release of damage-associated molecular patterns (DAMPs) such ATP, HMGB1 and HSP and CRT exposure on the outer cell surface (4). The emitted DAMPs promote the recruitment and maturation of antigen-presenting cells (eg,

DCs) $(5,6)$, which leads to optimal antigen presentation to $C D 8^{+} T$ cells $(7)$ and induction of antitumor immunity (8), resulting in significant suppression of tumor growth and/or regression of cancer and decreased risk of metastasis. The activated anticancer immunity aims to eradicate cells deep within the primary tumor and, therefore, significantly enhance PDT efficiency. The "gold standard' for determining the true immunogenicity of cell death requires the conduction of experimental studies in vivo (mouse prophylactic tumor vaccination model) (9). For this, immunocompetent mice are first vaccinated with PDT-treated cancer cells in one flank and 1 week later rechallenged with living cells of the same type in the other flank (10). Protection against tumor growth at the challenge site is interpreted as a sign of successful priming of the adaptive immune system (11). ${ }^{*}$ Examples of PSs with presumed but not fully proven immunogenic properties (lack of DAMPs expression and/or lack of immunogenicity either in vitro or in vivo). CD, cluster of differentiation; CRT, calreticulin; DC, dendritic cell; HMGB1, high-mobility group protein box 1; HSP, heat shock protein; hv, photons, IFN, interferon; IL, interleukin;.

decrease of tumor growth in the fibrosarcoma MCA205 murine prophylactic tumor vaccination model. ${ }^{46}$

Moreover, it is conceivable that PSs can simultaneously affect several cellular compartments. For instance, redaporfin specifically accumulates in the ER and Golgi apparatus and induces apoptosis. ${ }^{47}$ Dispersion of the Golgi apparatus or inhibition of its function significantly reduces the efficiency of redaporfin-based PDT. In the PDT reaction in a prophylactic tumor vaccination model using PDT-treated TC1 lung cancer cells, redaporfin acts as an ICD inducer that triggers eIF2a phosphorylation, DAMPs release (ATP, CRT, HMGB1) and decreased tumor growth. ${ }^{47}$

Of interest is that an approach that damages both lysosomes and mitochondria can be achieved by the simultaneous application of two PSs. In PDT, this approach has been realized by using the following pairs of PSs: Photofrin or N-aspartyl chlorin E6 (NPe6), which target lysosomes, and a benzoporphyrin derivative (BPD, Verteporfin), which targetets mitochondria. ${ }^{48-50}$ In contrast to the use of a single PS, this PDT protocol sequentially evoked lysosomal and then mitochondrial photodamage, which provided better tumor eradication. However, the question of whether this approach can activate ICD has not been raised. Sequential application of two PSs with different subcellular localization is a promising ICD-inducing strategy, and as greater understanding is gained, many more interesting and challenging findings are expected. 
In addition to the localization characteristics of PSs, it is important to mention that high doses of PSs increases the risk of side effects (eg, pain, erythema, non-scarring skin lesions and death of non-tumor cells in the vicinity of the light-exposed area). ${ }^{51}$ Therefore, it is important to select an optimal PS dose at which PDT induces ICD with minimal damage to normal cells. The efficacy of ICD induction during PDT may be non-linearly dependent on the PS dose.

It has been shown that a low dose of the non-porphyrinic PS OR141 in PDT induces a slower death of mouse SCC7 and human A431 SCC cells, but it provides a more rapid emission of DAMPs (HMGB1, ATP, annexin A1, Hsp90) and expression of major histocompatibility complex (MHC) I molecules (H2Kk). The subsequent inhibitory effects of the low dose on tumor growth in immunocompetent $\mathrm{C} 3 \mathrm{H} / \mathrm{HeNRj}$ mice was more pronounced than when a 10-fold higher dose was used. ${ }^{52}$ PSs might also be able to penetrate into normal cells, so the use of high PS doses can cause significant dark toxicity to normal noncancerous cells. This can be detrimental for several cell types, and particularly brain cells, as morphofunctional disorders in neuron-glial networks may lead to significant disruption of central nervous functions and aggravate the patient's condition. ${ }^{5354}$

The use of high doses of PS can be avoided by using nanostructures to deliver the PS directly to specific tumor cell compartments to trigger ICD while minimizing contact with normal cells. Therefore, to improve the efficiency of the PDT reaction, there is a need to develop nanosystems with an optimal combination of PSs and ICD inducers that will maintain the oxygen supply at the target location.

\section{CLASSES OF PHOTOSENSITIZERS IN PDT-INDUCED ICD}

ICD refers to an immunological characteristic of cell death that does not correlate with other features, including mechanism and manifestations, and can involve several cell death modalities (apoptosis, necroptosis, ferroptosis, pyroptosis) that stimulate a host immune response against antigens derived from dying/dead cancer cells. ${ }^{19} 2022245556$ The ability of anticancer treatment to efficiently trigger ICD is one of the key prerequisites for successful anticancer therapy. Although many cellular stressors can induce ICD, the specific pattern of the molecular players and particular death mechanisms depend on the treatment modality and probably on the cancer cell type as well. ${ }^{57}$ For cancer cells to be considered immunogenic, the following criteria must be fulfilled. ${ }^{4958}$ First, the cancer cells undergoing ICD in vitro must stimulate immune responses that protect mice against challenges with live tumor cells, that is, that they function as a vaccine. In this way, in vivo ICD must trigger a response of the innate and subsequently adaptive immune system that lead to suppression of tumor growth at the site rechallenged with cancer cells. Of note, APCs preloaded with dying/dead cancer cells can also be employed for vaccination. ${ }^{59}$ Thus, the concept of ICD implies activation of the innate and adaptive immune system components by actively or passively emitted DAMPs. Although the emission of DAMPs from PDTtreated cancer cells has been widely reported, the pattern of DAMPs varies depending on the treatment regimen and the type of cancer cells. The most universal feature of dying PDT-treated cancer cells is exposure of the calciumbinding protein CRT on the outer surface of the plasma membrane. ${ }^{43526061}$ CRT is normally localized in the ER lumen, but when it is exposed on the surface, it is recognized by low-density lipoprotein receptor-related protein 1 (LPR1, CD91) and serves as the 'eat me' signal for APCs. CRT exposure is attributed to ER stress caused by accumulation of misfolded proteins and the resultant unfolded protein response (UPR) ${ }^{43}{ }^{62-64}$ It should be noted that the detailed molecular mechanisms of the PDT-induced CRT exposure can differ depending on the type of PS. For example, CRT exposure on Rose Bengal acetate (RBA) treatment is accompanied by co-translocation of ER protein $57,{ }^{65}$ whereas during hypericin-based PDT this co-translocation is not detected. ${ }^{4366}$ Also, the phosphorylation of eukaryotic initiation factor $2 \alpha$ plays a crucial role in UPR induction and is commonly regarded as obligatory for CRT exposure. ${ }^{67}$ However, this phospohorylation can be absent on hypericin-based PDT. ${ }^{43}$ Interestingly, CRT can also be released by activated macrophages, on which it can bind to the surface of viable cells and thereby mediate their clearance. ${ }^{68} 69$

Other ER chaperones can also be exposed on the plasma membrane surface of dying cancer cells. PDTinduced externalization has been reported for HSPs, including HSP70, HSP90, HSP27, HSP34, HSP60 and HSP72/73. ${ }^{43} 6566$ 70-74 It is known that these DAMPs are required for presentation of TAA to APC, thus promoting the anticancer immune responses.

Other reported PDT-associated DAMPs include HMGB1 and ATP, which are emitted from PDT-treated dying/dead cells. ${ }^{46} 70$ Recently, it has been shown that photodithazine and photosens are also capable of inducing ICD associated with ATP and HMGB1 emission. ${ }^{46}$ HMGB1 can induce activation of innate immune responses by interaction with toll-like receptors 2 and 4 and possibly with other pattern recognition receptors on APC. However, ATP promotes the recruitment of APC by binding to their purinergic receptors, which is interpreted by APCs as a 'find me' signal. ATP can be either passively released from cells because of the loss of plasma membrane integrity or actively secreted; in the latter case, it is regulated by a specific signaling pathway. ${ }^{19}$ Like the CRT mechanism, the precise mechanism of ATP release under PDT treatment seems to have its specific features. For example, in contrast to the ICD induced by chemotherapeutics, ${ }^{76}$ hypericin-based PDT induces secretion of ATP in an autophagy-independent manner. ${ }^{77}$ All these data suggest that PDT based on different PSs efficiently induces the emission of the key DAMPs from cancer cells (figure 2). 
Another factor that may modulate anticancer immune responses to ICD, as well as ICD itself, is the PS dose and the light energy used for irradiation in PDT regimen. In fact, these two parameters affect the strength of cell death induction and determine how quickly cancer cells proceed to the late stages of cell death, ${ }^{24}$ which has been recently shown to be decisive in the immunogenicity of dying cancer cells. In this regard, it has been shown that the optimal radioimmunotherapy regimens are highly dependent on how the radiotherapy doses and fractionation schedules modulate type I IFN. ${ }^{78} 79$ Therefore, a better understanding of the correlation between ICD on the one hand and the PS dose and the light energy on the other will provide a deeper understanding of the molecular mechanism of immunogenicity. In turn, that will lead to the development of novel, more efficient therapeutic approaches that may have important implications for the choice of PDT regimens in the clinic to convert immunotherapy unresponsive patients into responders.

\section{Non-porphyrin PSs in ICD induction}

The first PS shown to induce ICD is hypericin, an anthraquinone derivative of natural origin with specific ER localization ${ }^{4366}$ (figure 2). It is still the most studied PS, and the molecular mechanisms underlying its induction of ICD and subsequent development of ICD have been at least partially elucidated. ${ }^{4366}{ }^{70}$ In their initial work, Garg et al showed that in T24 human bladder carcinoma cells in vitro, hypericin-based PDT can induce ICD with surface exposure of HSP70 and CRT as soon as $30 \mathrm{~min}$ after PDT, and that this is associated with the active secretion of ATP and passive release of CRT, HSP90 and HSP70. Co-incubation of PDT-treated dead cells with JAWSII murine DCs resulted in their phenotypic maturation $\left(\mathrm{CD} 80^{\text {high }}\right.$, CD83 ${ }^{\text {high }}, \mathrm{CD} 6^{\text {high }}$, MHC II $\left.^{\text {high }}\right)$ and functional stimulation $\left(\mathrm{NO}{ }^{\text {high }}, \mathrm{IL}-10^{\text {absent }}, \mathrm{IL}^{-1} \beta^{\text {high }}\right)^{436466}$ (table 1$)$. In vivo, they showed that cancer cells undergoing cell death after hypericin-based PDT are immunogenic in two different mouse models by using CT26 colon carcinoma cells and orthotopic glioma cells (GL261). The authors showed that dead/dying CT26 murine colon carcinoma cancer cells protected syngeneic mice against subsequent challenge with the same viable cell line, ${ }^{43}$ and the prophylactic efficacy of the ICD-based DC vaccine was demonstrated in the orthotopic GL261 murine glioma. It has been shown that the ICD-based DC vaccine induces an increase in brain infiltration with $\mathrm{CD}^{+}, \mathrm{CD}^{+}$and $\mathrm{CD}^{+}$T-lymphocytes, Th1 cells, CTLs and Th17 cells, along with a significant reduction in regulatory $\mathrm{T}$ cells. ${ }^{70}$ Re-exposure of splenocytic $\mathrm{T}$ cells to untreated glioma cells led to enhanced IFN- $\gamma$ production, which can be regarded as a sign of an immune memory response. These studies demonstrate that hypericin-based PDT efficiently induced ICD in several cancer models in vitro and in vivo.

The other promising non-porphyrin PS is benzophenazine OR141, ${ }^{80}$ which also localizes specifically in the ER. OR141 induces cell death mainly through the mammalian target of rapamycin signaling pathway and by inhibition of proteasomal deubiquitinases, resulting in ER stress. CRT exposure and release of HSP90, annexin A1, HMGB1 and ATP on treatment with OR141-PDT has been reported for several cell lines. ${ }^{5271}$ In a therapeutic vaccination model, dying cells induced marrow-derived dendritic cell maturation $\left(\mathrm{CD} 80^{\text {high }}, \mathrm{CD} 86^{\text {high }}\right.$, MHC $\mathrm{II}^{\text {high }}$ ) in vitro as well as in vivo and led to a delay of tumor growth and an increase in survival of syngeneic mice with SCC7 murine head and neck carcinoma ${ }^{52}$ or Ab1 mesothelioma $^{81}$ (table 1). Importantly, the DC-based vaccine proved to be even more effective than vaccination with the PDT-treated carcinoma cells themselves. ${ }^{71}$

ICD can also be induced by PDT based on 8-methoxypsoralen (8-MOP). This PS has a different mechanism of photo-induced toxicity: it does not require oxygen but intercalates into DNA and forms cross-links with one or two DNA strands on UVA irradiation. 8-MOP is applied in extracorporeal photochemotherapy for cutaneous T-cell lymphoma; white blood cells in peripheral blood are exposed to 8-MOP-UVA and then infused into the patient vasculature. 8-MOP-UVA treatment of murine melanoma cells was shown to result in exposure of CRT and emission of ATP, HMGB1 and type I IFN ${ }^{82}$ (table 1). In addition, a prophylactic vaccination model proved that ICD can be induced by 8-MOP-UVA treatment in several melanoma cell lines. ${ }^{82}$ In another study, dying YUMM1.7 murine melanoma cells or MC38 murine colon adenocarcinoma cells pretreated with 8-MOP-UVA were co-incubated with platelet-containing peripheral blood mononuclear cells from tumor-bearing mice. Intravenous reinfusion of the cell mixture into the tumor-bearing mice (multiply repeated procedure) induced a significant delay in tumor growth. ${ }^{83}$ These data indicate that the selective antitumor effects of extracorporeal photochemotherapy are based on the induction of ICD and suggest that extracorporeal photochemotherapy of cutaneous $\mathrm{T}$ cell lymphomas is a potential therapeutic approach. The opposite results were obtained for 8-MOP-UVA-treated peripheral blood mononuclear cells from patients with graft versus host disease and alloreactive T cells. ${ }^{84}$ Despite pronounced expression of several DAMPs by dying cells, including CRT and HMGB1, and their engulfment by APC, these dying cells did not stimulate DC maturation. These data may be explained by the stage of cell death. It is conceivable that the cell death stage at which dying cells were co-cultured with DC was not immunogenic enough to induce activation/maturation of DCs. In this regard it has been shown that only cells in the early death stage are immunogenic. ${ }^{24}$

Pronounced production of DAMPs has been reported after treatment with the non-porphyrin PSs listed above, and after application of RBA, a fluorescein derivative. ${ }^{65}$ The authors showed that the pattern of DAMPs differs between cells dying by apoptosis and those undergoing autophagy: apoptotic cells exposed CRT while autophagic cells did not, and they were not able to release ATP. Yet, the immunogenicity of cell death induced by RBA-ICD must be demonstrated in vivo. ${ }^{85} 86$ 


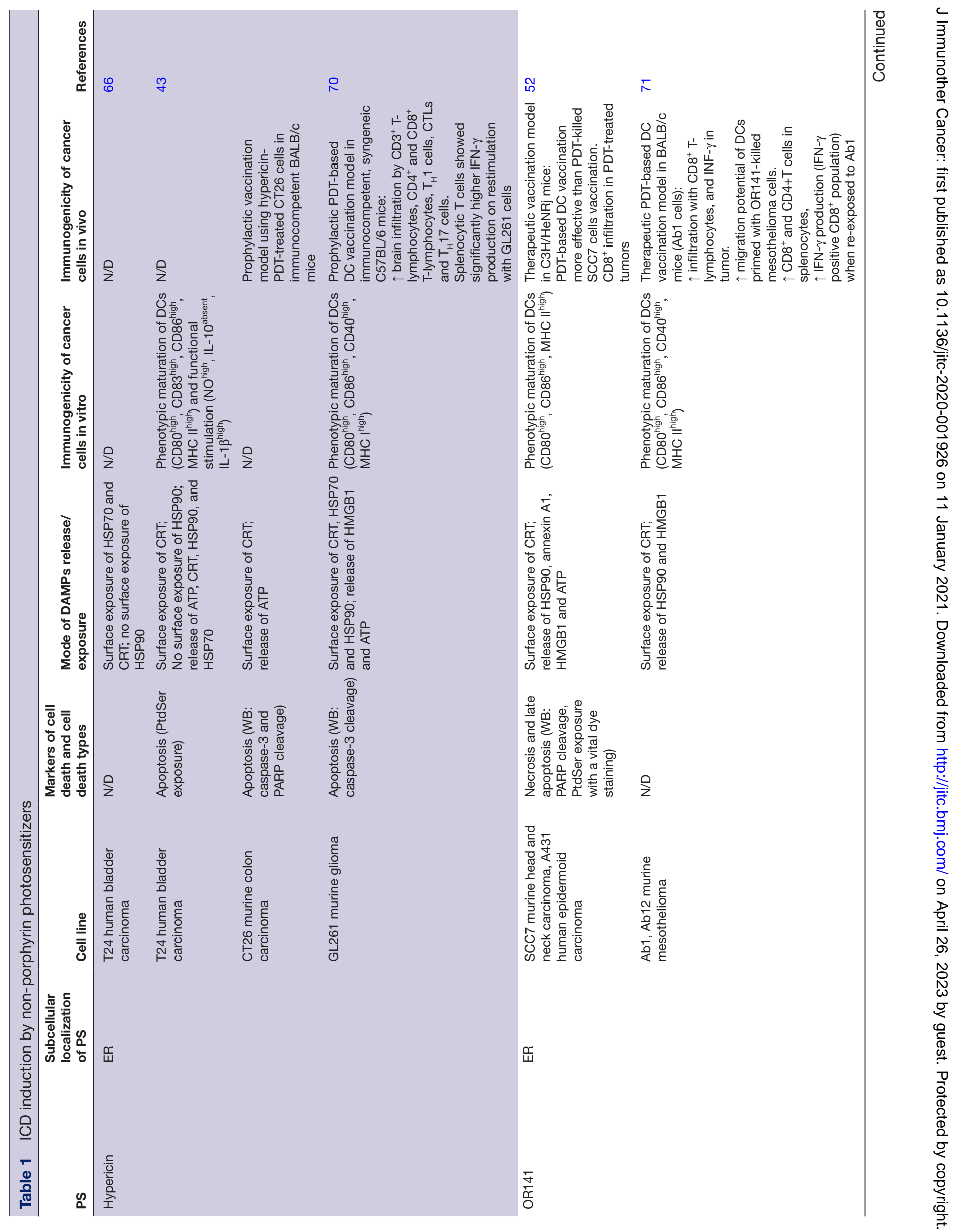




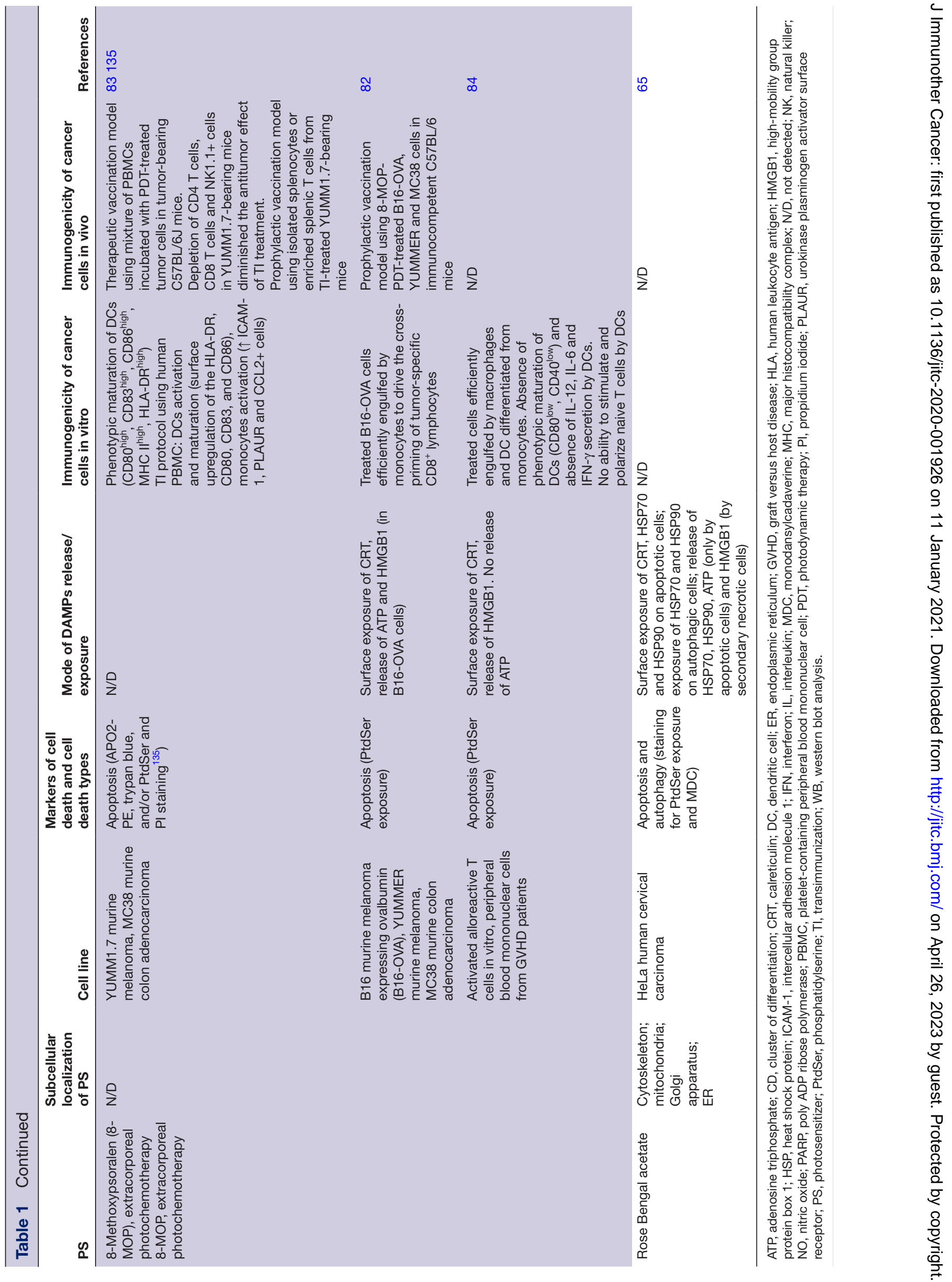




\section{ICD induction by porphyrin photosensitizers of the first} generation and second generation

Several porphyrin-derived PSs have shown the ability to induce ICD in PDT-treated cells (figure 2). As early as 2004, it was reported that treatment with the first-generation porphyrin PS, photofrin, led to the exposure of a number of HSPs on the surface of cancer cells and promoted their engulfment by DCs, followed by DC maturation manifested in IL-12 production. ${ }^{73}$ Of interest, intratumorally injected DCs homed to regional and distant lymph nodes and activated both spontaneous (NK cells) and specific $\left(\mathrm{CD}^{+} \mathrm{T}\right.$ cells) cytotoxicity toward tumor cells. This initial work on photofrin was further extended by others. ${ }^{60}{ }^{74}$ It has been shown that photofrin-based PDT of Lewis lung carcinoma cells induced release of HSPs, and surface exposure of CRT in vitro and in vivo within 1 hour after PDT, as well as an increase of HMGB1 in plasma. ${ }^{60}$ These data indicate that photofrin is a potent inducer of ICD.

One of the promising modes of PDT is based on exogenous aminolevulinic acid (ALA), a low-molecular-weight precursor of protoporphyrin IX. This compound does not accumulate in sufficient amounts in cells with normal metabolism, but in cancer cells its concentration rises significantly mainly due to lowered activity of ferrochelatase, which converts protoporphyrin IX into heme. ALAPDT induced ICD in two vaccination mouse models. First, ALA-PDT-treated murine SCG cells injected into SKH-1 mice provided complete protection in the tumor prophylactic vaccination model ${ }^{75}$ (table 2 ). Second, vaccination of mice with DCs prestimulated by ALA-PDT-treated SSC cells was also shown to be effective against rechallenge with cancer cells. This prophylactic vaccination efficacy is in line with the production of DAMPs, including surface exposure of CRT by ALA-PDT-treated cancer cells of various origin, ${ }^{7587}$ as well as HSP70, ${ }^{707588}$ and release of $\mathrm{ATP}^{70}$ and $\mathrm{HMGB}^{75}$ (table 2). An increase in IFN-I transcription was reported for murine melanoma cells treated with 5-methylaminolevulinic acid (Me-ALA), a derivative of ALA with similar biological properties. ${ }^{87}$ The expression of IFN- $\alpha /$ IFN- $\beta$ correlated with the doses of Me-ALA and was specific for PDT-treated cells but not for cells treated with doxorubicin, a bona fide chemotherapeutic ICD inducer. It has been proposed that IFN-I acts in an autocrine loop to induce the apoptosis of treated cells, as well as in a paracrine mode stimulating DC migration (table 2). ${ }^{87}$

Recently, ICD induction was shown for PDT based on several second-generation porphyrin PSs. In this regard, PDT based on glucose-linked tetra(fluorophenyl)chlorin (G-chlorin) induced an ICD in CT26 murine colon carcinoma cells characterized by surface exposure of CRT and release of $\mathrm{HMGB}^{61}$ (table 2). Vaccination of immunocompetent mice with CT26 cells pretreated with G-chlorin-PDT protected them against a subsequent challenge with live CT26 cells. The role of DAMPs production by these dead tumor cells was demonstrated by the absence of a vaccination effect when tumor cells in which the CRT or HMGB1 gene was knocked-down were used in the vaccination experiment.

Another study compared ICD induction by PDT based on chlorin $e 6$ derivative photodithazine with that based on the phthalocyanine dye photosens. ${ }^{46}$ The authors showed that both PSs induce ICD associated with DAMPs emission in murine MCA205 fibrosarcoma and GL261 glioma cells. ${ }^{46}$ However, the intensity and timeline of CRT exposure and release of ATP and HMGB1 by cancer cells depended on both the cell line and the PS. Photosensbased PDT led to a more active engulfment of dead/ dying cancer cells by BMDCs and, at least for GL261 glioma cells, a larger increase in the expression of CD40 and CD86 co-stimulatory molecules on the surface of BMDCs. However, both PSs were comparably efficient in a mouse tumor prophylactic vaccination model. The most intriguing aspect of the ICD-inducing capability of photosens is that it has strong vesicular localization. The negative charge and hydrophilic properties of photosens hamper its escape from endosomes and lysosomes. In contrast to most of the PSs studied, the primary target of photosens-PDT is not the ER. Importantly, the cell death induced by photosens combines features of apoptosis and ferroptosis, as it was blocked by specific inhibitors of apoptosis (zVAD-fmk) and ferroptosis (ferrostatin-1 and deferoxamine $)^{46}$ (table 2). This suggests that certain PSs can induce ICD with mixed cell-death phenotypes. This can be particularly interesting when cancer cells develop resistance to a specific type of cell death. In such cases, triggering several cell-death types makes it possible to circumvent cell death resistance and may increase the efficiency of cell death induction in cancer cells.

A new combined treatment strategy has been proposed based on two PSs and on the ability of PDT to directly kill tumor cells and to initiate antitumor immunity. ${ }^{89}$ The pheophorbide-derivative 2-[1-hexyloxyethyl]-2-devinyl pyropheophorbide- $\alpha$ (HPPH) and photofrin were applied for two-step PDT: an immune-enhancing lowdose PDT treatment was followed by a tumor-controlling high-dose PDT treatment (table 2). This combined PDT regimen led to higher numbers of activated tumorspecific $\mathrm{CD}^{+} \mathrm{T}$ cells in the tumor-draining lymph nodes, and this coincided with reduced metastatic ability of the tumor (ie, murine Colon26-HA and mammary 4T1 carcinomas). It was also associated with enhanced long-term control of tumor growth and resistance of the cured mice to tumor rechallenge. This work indicates that combined PDT may provide an effective adjuvant for therapies that fail to stimulate the host antitumor immune response.

There are several intriguing findings supporting a rationale for combination treatments of PDT based on radachlorin (also known as bremachlorin) and immunotherapy. When the lysates of TC-1 cells carrying human papillomavirus $16 \mathrm{E} 7$ were induced by radachlorin-based PDT in combination with the immuno-adjuvant CpGoligodeoxynucleotide (ODN), tumor growth after both prophylactic and therapeutic vaccination doses in vivo were significantly suppresssed. ${ }^{90}$ Interestingly, PDT-cell 


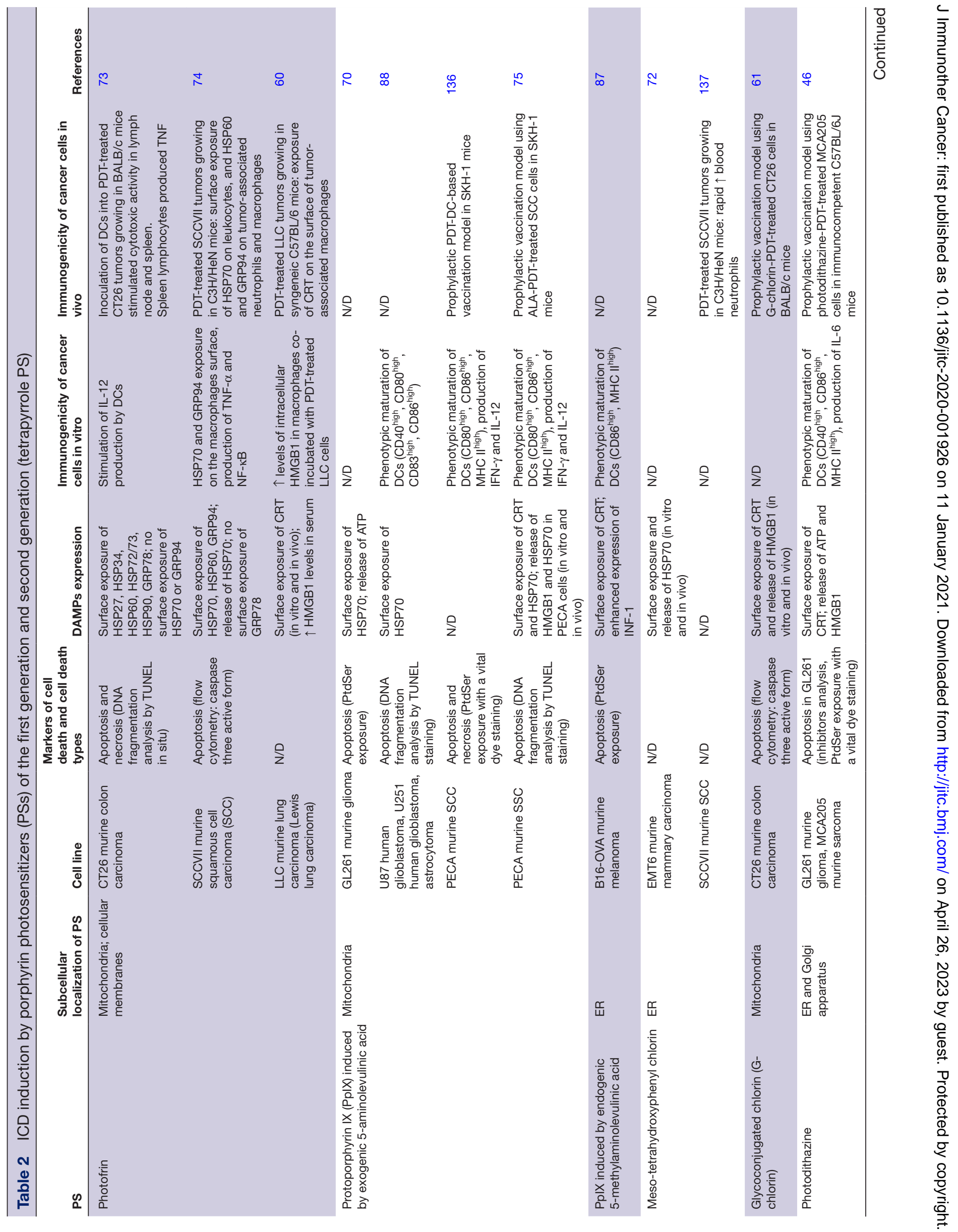


lysates induced release of DAMPs, including HSP70, and in combination with ODN injection, IFN- $\gamma$ production and cytotoxic $\mathrm{T}$ lymphocytes responses $\left(\mathrm{CD} 8^{+} \mathrm{T}\right.$ cells) were stronger than when ODN or PDT was used alone. ${ }^{90}$ Similar effects were shown for a combination of radachlorin-based PDT of TC-1 cells and adenoviral delivery of interleukin-12 (AdmIL-12) in a mouse tumor model. ${ }^{91}$ In that work, combined treatment significantly increased the production of IFN- $\gamma$ and TNF- $\alpha$ and the expansion of the CTL subset mediated by $\mathrm{CD}^{+} \mathrm{T}$ cells, resulting in complete regression of tumors of $9 \mathrm{~mm}$ in mice ${ }^{91}$ In another study in the mouse model of therapeutic vaccination, RMA cells (aggressive T-cell lymphoma cell line induced by Rauscher murine leukemia virus) were treated with bremachlorin-based PDT in combination with synthetic long peptides containing epitopes from tumor antigens. This procedure resulted in efficient induction a significant $\mathrm{CD}^{+} \mathrm{T}$-cell response against the tumor. $^{92}$ All these results indicate that contemporary antitumor treatments should be based on a combination of several antitumor strategies where activation of the immune system is crucial.

\section{Third-generation PSs: enhancing immunogenicity by use of nanoconstructs}

The concept of targeted PDT has been actively pursued in recent years. This approach is closely linked to the design of the third-generation PSs, namely, liposomal forms of PSs, PSs in combination with nanocarriers and PSs conjugated with sugar molecules, monoclonal antibodies or peptides (figure 2). The advantages of targeted PDT compared with the insufficient selectivity of firstgeneration and second-generation PSs are improvement of PS pharmacokinetics, significant reduction in the required dose of the PSs and decrease of side effects. ${ }^{38}$ One of the requirements for an 'ideal' PS is that it has absorption in the near infra-red spectrum (NIR) $(600-1000 \mathrm{~nm})$. In this range, light is slightly scattered by most tissues and poorly absorbed by endogenous chromophores such as melanin, hemoglobin and cytochromes. Consequently, far-red and NIR light can penetrate well in human tissue and can be selectively absorbed by photosensitizing agents such as porphyrins, chlorins, phthalocyanines and naphthalocyanines. ${ }^{29}$ In recent decades, researchers in the field of PDT have decided to combine the use of NIR PSs with their delivery to the target organs by antibodies or nanocarriers. This approach has increased the efficiency of PDT and broadened the boundaries for the treatment of tumors at different sites. ${ }^{93}$ The strategy of using NIR PSs conjugated with the guiding antibody has been called near-infrared photoimmunotherapy (NIRPIT).$^{94}$ Notably, NIR-PIT has been shown to induce ICD. For instance, Ogawa $e t a \ell^{5}$ revealed that NIR-PIT with TraIR700 induces translocation of DAMPs (CRT, Hsp70 and Hsp90) to the cell surface and is associated with the rapid release of ATP and HMGB1, followed by maturation of DCs (table 3). 


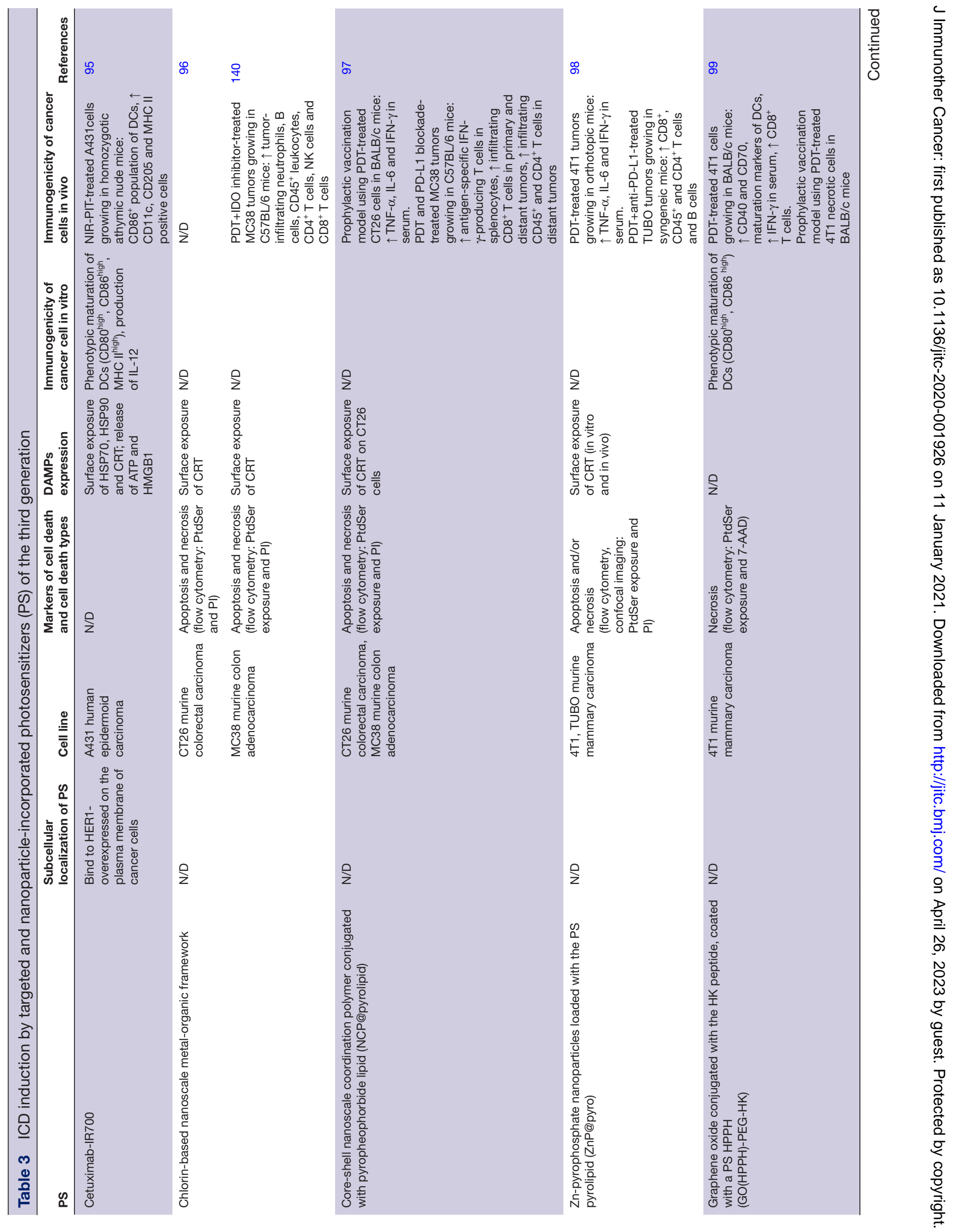




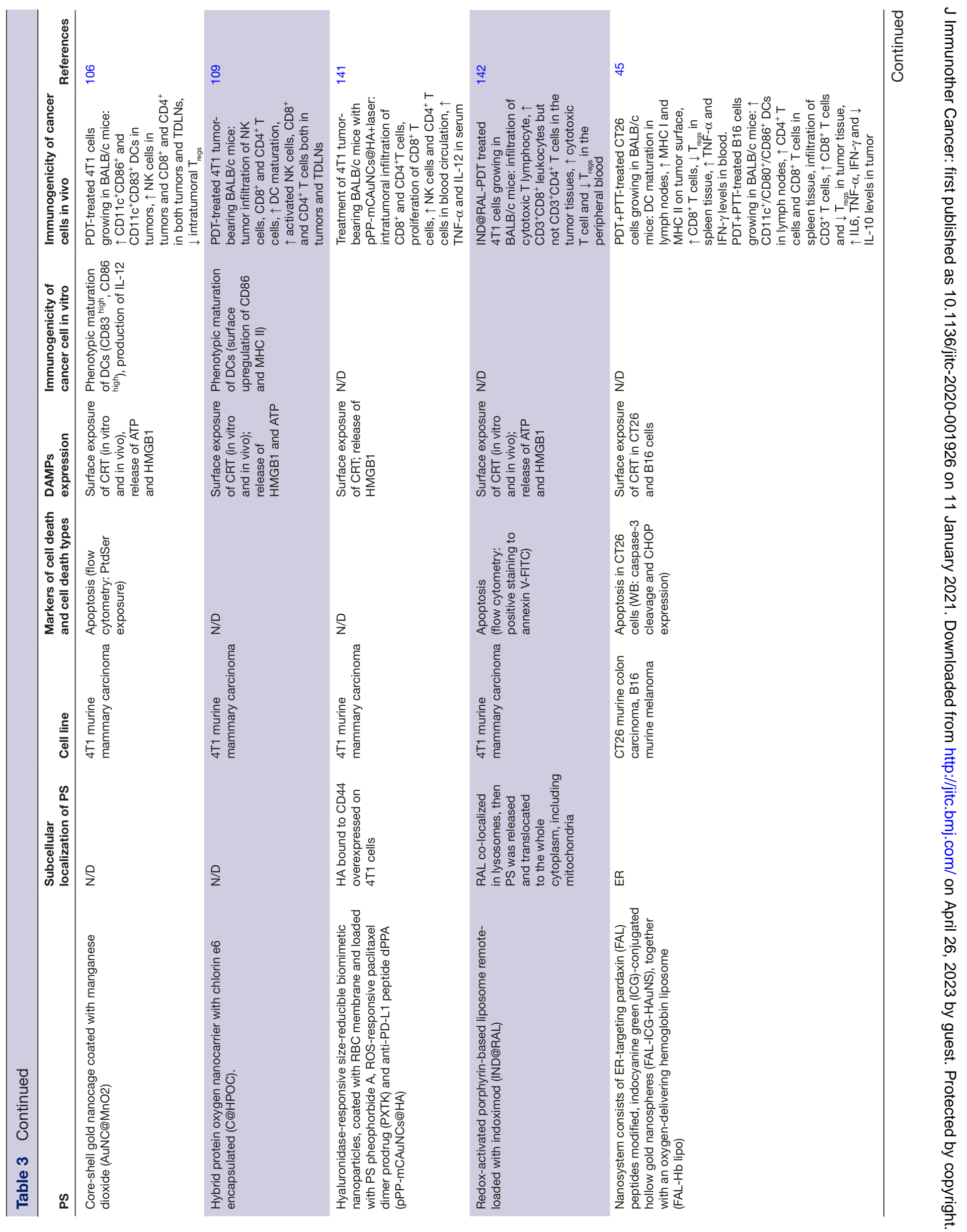




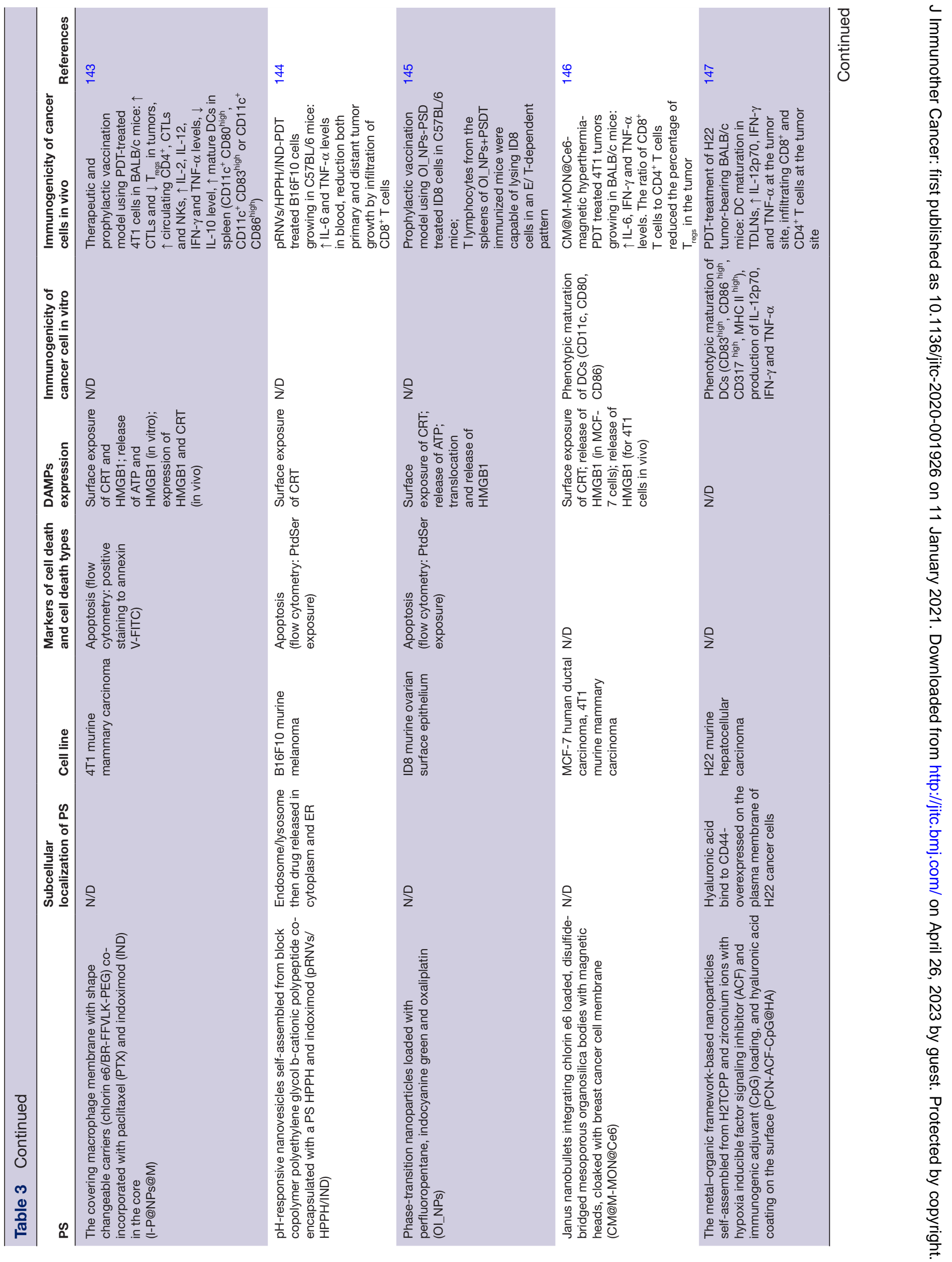




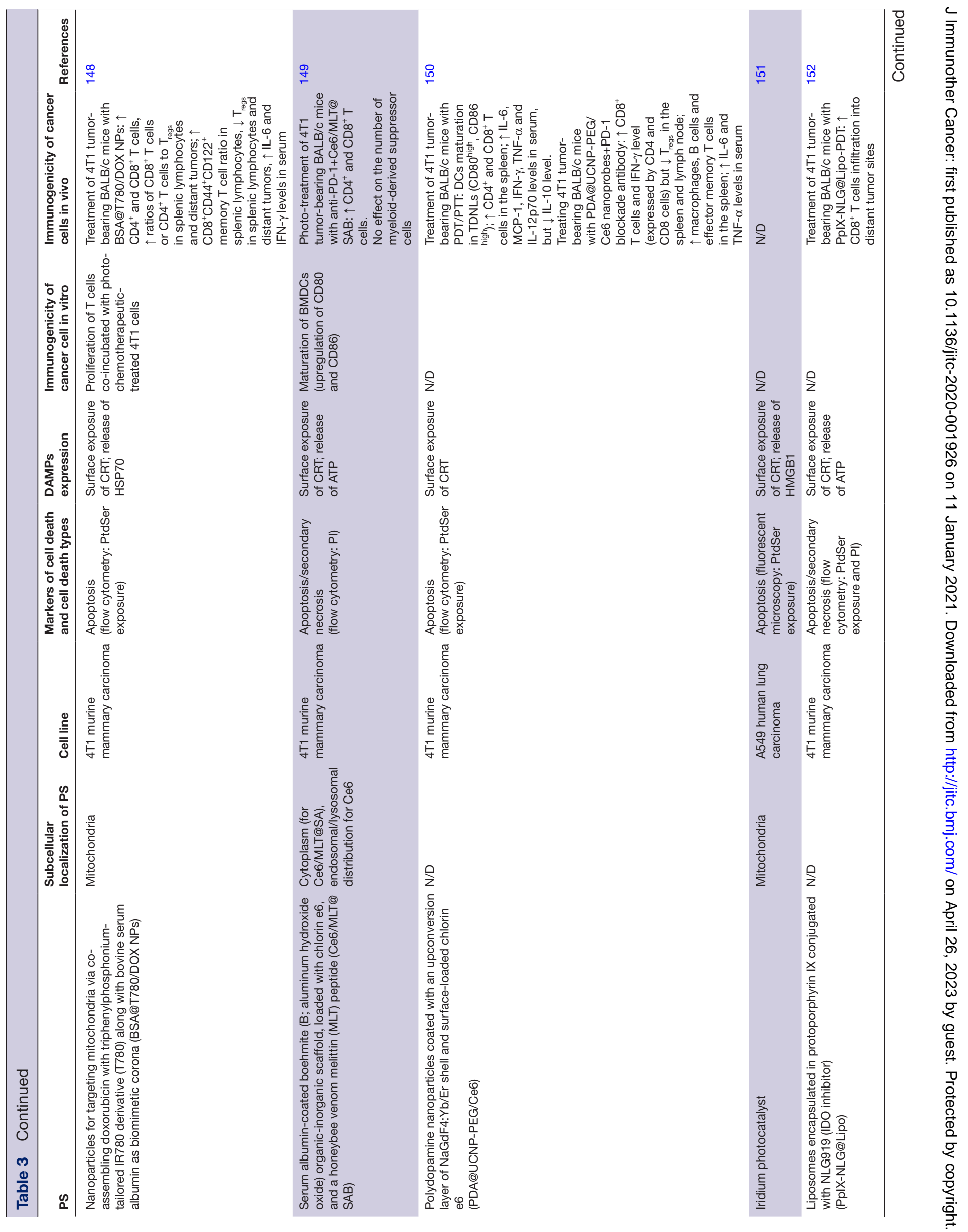




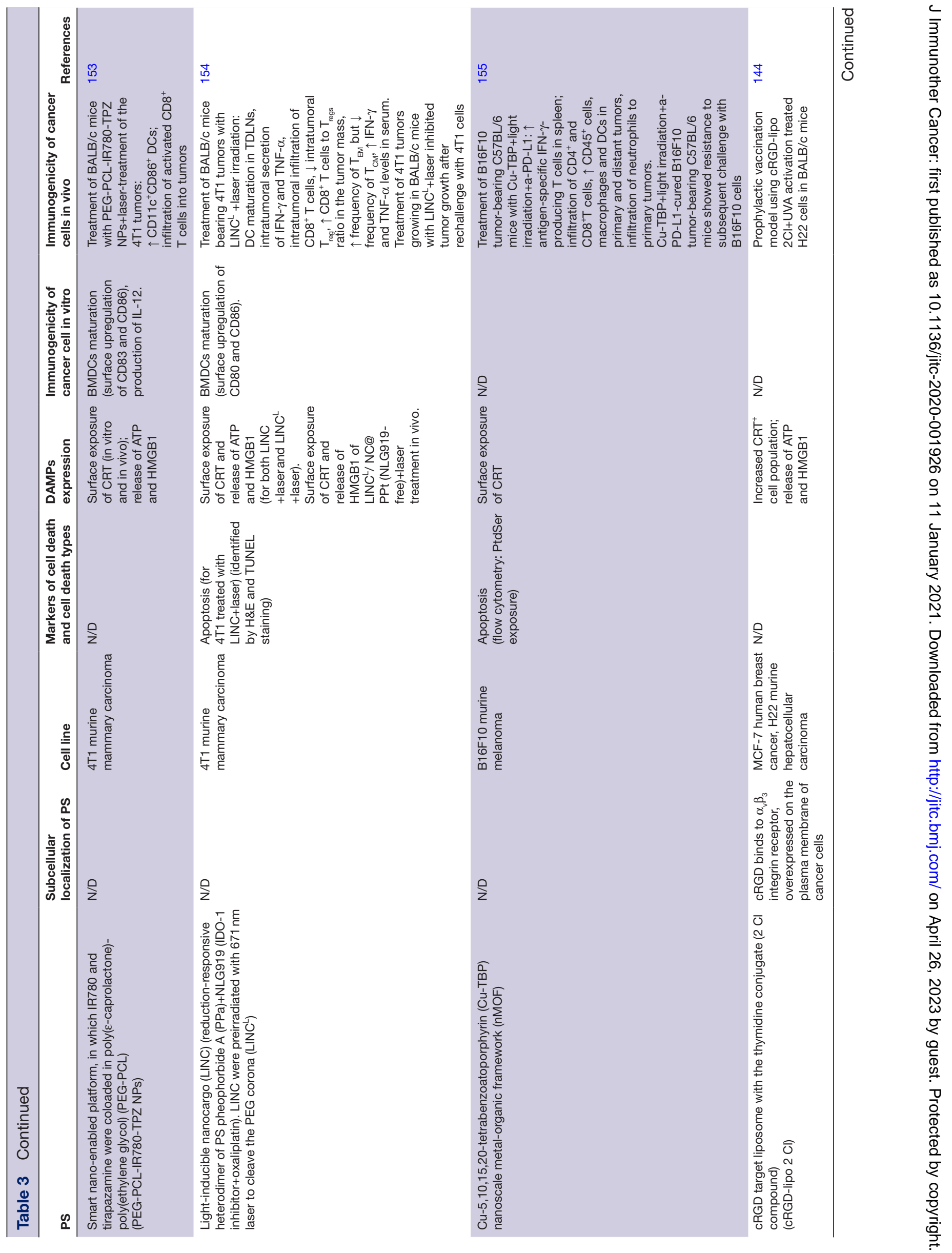




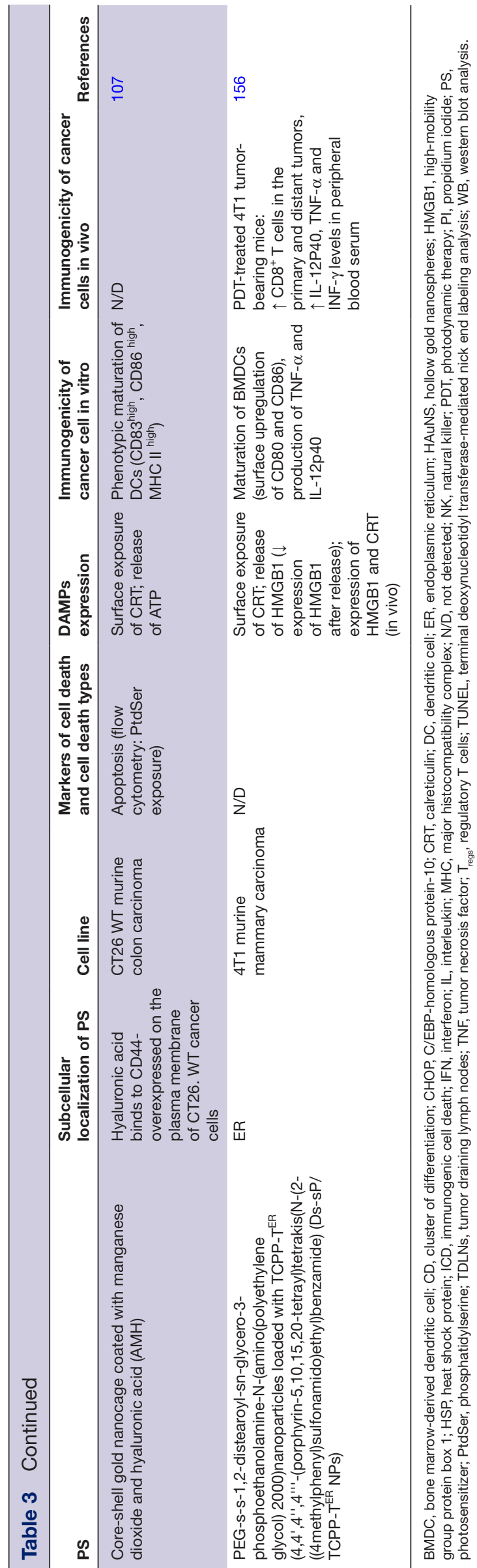

Increased absorption in the NIR spectrum range can also be achieved by using a nanoscale metal-organic framework (NMOF). For instance, Lu et al demonstrated that the application of porphyrin-based NMOF, DBC$\mathrm{UiO}$, leads to an increase in the extinction coefficient ${ }^{96}$ (table 3). This indicates that these compounds may be useful for medical procedures based on light absorption in NIR tissue transparency window. In addition to changes in the photophysical properties of such structures, the increase in PDT efficiency was associated with CRT surface exposure and ICD induction.

Another approach for ICD induction in PDT is the use of checkpoint inhibitors such as antibodies inhibiting programmed cell death protein 1 (PD-1)/programmed death-ligand 1 (PD-L1). He et al reported the use of nanoscale coordination polymer core-shell nanoparticles carrying oxaliplatin in the core and a PS pyropheophorbide-lipid conjugate (pyrolipid) in the shell (NCP@pyrolipid) in combination with anti-PD-L1 therapy. This induced CRT surface exposure, effective antitumor vaccination and an abscopal effect. ${ }^{97} \mathrm{~A}$ similar effect was described in another study in which Zn-pyrophosphate (ZnP) nanoparticles were loaded with pyrolipid (ZnP@pyro) in combination with anti-PD-L1 therapy ${ }^{98}$ (table 3 ).

Besides combining PDT with checkpoint inhibitors, several studies describe the use of peptide-conjugated PSs. For example, graphene oxide coated with a photosensitizer (HPPH) and conjugated with a HK peptide (tumor integrin $\alpha v \beta 6$-targeting peptide) was able to destroy the primary tumor site and residual tumor cells, prevent the occurrence of remote metastases, activate the host's antitumor immunity and suppress tumor relapse by stimulating immunological memory in mice. ${ }^{99}$ All these results indicate that third-generation PSs hold promise for enhancing the immunogenicity of dying cancer cell therapy and for combining PDT with checkpoints inhibitors. Nevertheless, most studies have been done on mouse models, and this strategy requires validation in clinical studies. It should be noted that nanocarriers can also be used to increase the immunogenicity of dying cancer cells, ${ }^{39}$ and this is an exciting area for future research.

\section{CHALLENGES AND FUTURE TRENDS IN PDT-INDUCED ICD}

The efficiency of PDT induction of ICD can be compromised by hypoxia, which often occurs in the tumor microenvironment. The hypoxic process is mediated by the rapid proliferation of cancer cells and leads to a significant imbalance between oxygen supply and demand and pronounced metabolic alterations. ${ }^{100}$ The development of oxygen deficiency in the tumor microenvironment is also facilitated by pathophysiological changes such as deformation of tumor blood vessels due to an imbalance between pro-angiogenic and anti-angiogenic signaling, physical compression and disruption of the functioning of the lymphatic system. ${ }^{101}{ }^{102}$ Since PDT treatment relies on an oxygen supply for induction of cytotoxic 
ROS production, hypoxia significantly diminishes PDT efficiency for solid tumors. Therefore, it is important to develop strategies to overcome this hypoxia-related limitation of PDT. The effectiveness of PDT in triggering ICD can be improved by the introduction of agents that increase the oxygen concentration in the tumor microenvironment, a strategy named oxygen-boosted PDT. One approach is to develop versatile oxygen carriers or generators, such as nanoparticles based on perfluocarbon, which is used in artificial blood in clinical applications. ${ }^{103}$ Thanks to its high oxygen capacity, perfluocarbon provides a long ${ }^{1} \mathrm{O}_{2}$ lifetime, which results in long-lasting photodynamic effects. ${ }^{104}$ However, in that study, though the therapeutic efficacy of PDT was established in experiments on tumor-bearing mice, the immunogenicity of tumor cell death was not examined. Therefore, additional studies are needed to understand whether this strategy can induce ICD.

Other strategies are linked to the creation of nanoparticles based on manganese dioxide $\left(\mathrm{MnO}_{2}\right) \cdot \mathrm{MnO}_{2}$ degradation in the acidic and $\mathrm{H}_{2} \mathrm{O}_{2}$-rich tumor microenvironment generates sufficient oxygen and increases ROS production, which in turn increases PDT efficacy. In addition, the $\mathrm{Mn}$ (II) ion reduced from $\mathrm{Mn}$ (IV) in response to increased acidic $\mathrm{H}_{2} \mathrm{O}_{2}$ provides an opportunity to carry out selective MRI in vivo. ${ }^{105}$ Of interest, core-shell gold nanocages encapsulated in $\mathrm{MnO}_{2}\left(\mathrm{AuNC} @ \mathrm{MnO}_{2}\right)$ altered the hypoxic and immunosuppressive tumor microenvironment and demonstrated reliable PDT and ICD effects. Oxygen-boosted PDT based on such nanoparticles is characterized by the emission of DAMPs such as CRT, ATP and HMGB1, followed by DC maturation and subsequent effector cell activation, including $\mathrm{CD} 8^{+}$and $\mathrm{CD} 4^{+} \mathrm{T}$ cells and NK cells. It has been shown that this provoked an antitumor immune response and effectively inhibited tumor growth and recurrence in two different tumor models (mice with CT26 colorectal and 4T1 mammary carcinomas). ${ }^{106107}$

Oxygen supply to the tumor microenvironment can also be augmented by using hemoglobin-based nanostructures. Directed delivery of hemoglobin to tumor cells via hybrid nanostructures ensures gradual $\mathrm{O}_{2}$ release in a hypoxic environment and significantly enhances ROS production during PDT. ${ }^{108}{ }^{109}$ It was also shown that chlorin e6-based PDT can trigger an ICD characterized by DAMPs release (CRT, HMGB1, ATP), DC maturation and activation of $\mathrm{CD}^{+}$and $\mathrm{CD}^{+} \mathrm{T}$ lymphocytes and NK cells in vivo. Activation of the immune system by hemoglobinbased nanostructures was shown to eradicate primary tumors and effectively suppress distant tumor growth and lung metastasis in a murine metastatic triple-negative breast cancer model. ${ }^{109}$ Thus, overcoming hypoxia in the tumor microenvironment is essential for increasing PDT efficiency. Development of hybrid systems based on nanoconstructs that can relieve hypoxia and include an immunological component is the most promising strategy, and we may see a new milestone for PDT in anticancer treatment in the near future.
In conclusion, the insights from the last several years increasingly support the idea that PDT is a powerful strategy for inducing ICD in experimental cancer therapy. However, most studies have focused on mouse models, but it is necessary to validate this strategy in clinical settings. Moreover, further insights into the interplay between PDT and oxygen-boosted therapy may provide new ground for the development of novel cancer immunotherapy. PDT and ICD represent a challenging research area with many possible promising future applications in the treatment of cancer.

Correction notice This article has been corrected since it first published. The provenance and peer review statement has been included.

Contributors RA, TM, NS, IB and MV: drafted the manuscript and the figures and tables. DK: designed and supervised the study and revised the manuscript.

Funding The study was supported by a grant from Russian Science Foundation (RSF, project no.18-15-00279).

Competing interests None declared.

Patient consent for publication Not required.

Provenance and peer review Not commissioned; externally peer reviewed.

Open access This is an open access article distributed in accordance with the Creative Commons Attribution Non Commercial (CC BY-NC 4.0) license, which permits others to distribute, remix, adapt, build upon this work non-commercially, and license their derivative works on different terms, provided the original work is properly cited, appropriate credit is given, any changes made indicated, and the use is non-commercial. See http://creativecommons.org/licenses/by-nc/4.0/.

ORCID iD

Dmitri V. Krysko http://orcid.org/0000-0002-9692-2047

\section{REFERENCES}

1 Wei SC, Levine JH, Cogdill AP, et al. Distinct cellular mechanisms underlie anti-CTLA-4 and anti-PD-1 checkpoint blockade. Cell 2017;170:1120-33.

2 Chamoto K, Chowdhury PS, Kumar A, et al. Mitochondrial activation chemicals synergize with surface receptor PD-1 blockade for T cell-dependent antitumor activity. Proc Natl Acad Sci U S A 2017;114:E761-70.

3 Galluzzi L, Buqué A, Kepp O, et al. Immunogenic cell death in cancer and infectious disease. Nat Rev Immunol 2017;17:97-111.

4 Galluzzi L, Vitale I, Warren S, et al. Consensus guidelines for the definition, detection and interpretation of immunogenic cell death. $J$ Immunother Cancer 2020;8:e000337-000337.

5 Krysko DV, Vandenabeele P. Clearance of dead cells: mechanisms, immune responses and implication in the development of diseases. Apoptosis 2010;15:995-7.

6 Bloy N, Garcia P, Laumont CM, et al. Immunogenic stress and death of cancer cells: contribution of antigenicity vs adjuvanticity to immunosurveillance. Immunol Rev 2017;280:165-74.

7 Tolerance MP. Danger, and the extended family. Annu Rev Immunol 1994;12:991-1045.

8 Matzinger P. The danger model: a renewed sense of self. Science 2002;296:301-5.

9 Krysko DV, Agostinis P, Krysko O, et al. Emerging role of damageassociated molecular patterns derived from mitochondria in inflammation. Trends Immunol 2011;32:157-64.

10 De Munck J, Binks A, McNeish IA, et al. Oncolytic virus-induced cell death and immunity: a match made in heaven? J Leukoc Biol 2017;102:631-43.

11 Vénéreau E, Ceriotti C, Bianchi ME. Damps from cell death to new life. Front Immunol 2015;6.

12 Patel S. Danger-Associated molecular patterns (DAMPs): the derivatives and triggers of inflammation. Curr Allergy Asthma Rep 2018;18:018-817.

13 Krysko O, Løve Aaes T, Bachert C, et al. Many faces of DAMPs in cancer therapy. Cell Death Dis 2013;4:156.

14 Fucikova J, Becht E, Iribarren K, et al. Calreticulin expression in human Non-Small cell lung cancers correlates with increased 
accumulation of antitumor immune cells and favorable prognosis. Cancer Res 2016;76:1746-56.

15 Garg AD, Galluzzi L, Apetoh L, et al. Molecular and translational classifications of DAMPs in immunogenic cell death. Front Immunol 2015;6.

16 Muth C, Rubner Y, Semrau S, et al. Primary glioblastoma multiforme tumors and recurrence: Comparative analysis of the danger signals HMGB1, HSP70, and calreticulin. Strahlenther Onkol 2016;192:146-55.

17 Vandenabeele P, Vandecasteele K, Bachert C, et al. Immunogenic Apoptotic Cell Death and Anticancer Immunity. In: Gregory CD, ed. Apoptosis in cancer pathogenesis and anti-cancer therapy: new perspectives and opportunities. Cham: Springer International Publishing, 2016: 133-49.

18 Inoue $\mathrm{H}$, Tani K. Multimodal immunogenic cancer cell death as a consequence of anticancer cytotoxic treatments. Cell Death Differ 2014;21:39-49.

19 Krysko DV, Garg AD, Kaczmarek A, et al. Immunogenic cell death and DAMPs in cancer therapy. Nat Rev Cancer 2012;12:860-75.

20 Krysko O, Aaes TL, Kagan VE, et al. Necroptotic cell death in anticancer therapy. Immunol Rev 2017;280:207-19.

21 Kaczmarek A, Vandenabeele P, Krysko DV. Necroptosis: the release of damage-associated molecular patterns and its physiological relevance. Immunity 2013;38:209-23.

22 Aaes TL, Kaczmarek A, Delvaeye T, et al. Vaccination with Necroptotic cancer cells induces efficient anti-tumor immunity. Cell Rep 2016;15:274-87.

23 Friedmann Angeli JP, Krysko DV, Conrad M. Ferroptosis at the crossroads of cancer-acquired drug resistance and immune evasion. Nat Rev Cancer 2019;19:405-14.

24 Efimova I, Catanzaro E, Van der Meeren L, et al. Vaccination with early ferroptotic cancer cells induces efficient antitumor immunity. $J$ Immunother Cancer 2020;8:e01369.

25 Agostinis P, Berg K, Cengel KA, et al. Photodynamic therapy of cancer: an update. CA Cancer J Clin 2011;61:250-81.

26 Yakubovskaya RI, Morozova NB, Pankratov AA, et al. Experimental photodynamic therapy: 15 years of development. Russ $J$ Gen Chem 2015;85:217-39.

27 Mallidi S, Anbil S, Bulin A-L, et al. Beyond the barriers of light penetration: strategies, perspectives and possibilities for photodynamic therapy. Theranostics 2016;6:2458-87.

28 Cramer SW, Chen CC. Photodynamic therapy for the treatment of glioblastoma. Front Surg 2020;6.

29 Hamblin MR. Photodynamic Therapy for Cancer: What's Past is Prologue. Photochem Photobiol 2020;96:506-16.

30 Rkein AM, Ozog DM. Photodynamic therapy. Dermatol Clin 2014:32:415-25.

31 de Oliveira AB, Ferrisse TM, Marques RS, et al. Effect of photodynamic therapy on microorganisms responsible for dental caries: a systematic review and meta-analysis. Int J Mol Sci 2019;20:3585.

32 Cieplik F, Deng D, Crielaard W, et al. Antimicrobial photodynamic therapy - what we know and what we don't. Crit Rev Microbiol 2018:44:571-89.

33 Gomes-da-Silva LC, Kepp O, Kroemer G. Regulatory approva of photoimmunotherapy: photodynamic therapy that induces immunogenic cell death. Oncoimmunology 2020;9:1841393.

34 Schaffer P, Batash R, Ertl-Wagner B, et al. Treatment of cervix carcinoma FIGO IIIB with Photofrin II as a radiosensitizer: a case report. Photochem Photobiol Sci 2019;18:1275-9.

35 Liu H, Liu Y, Wang L, et al. Evaluation on short-term therapeutic effect of 2 porphyrin Photosensitizer-Mediated photodynamic therapy for esophageal cancer. Technol Cancer Res Treat 2019;18:153303381983198.

36 Sun BO, LI WEI, Liu N. Curative effect of the recent Photofrin photodynamic adjuvant treatment on young patients with advanced colorectal cancer. Oncol Lett 2016;11:2071-4.

37 Toratani S, Tani R, Kanda T, et al. Photodynamic therapy using Photofrin and excimer dye laser treatment for superficial oral squamous cell carcinomas with long-term follow up. Photodiagnosis Photodyn Ther 2016;14:104-10.

38 Chilakamarthi U, Giribabu L. Photodynamic therapy: past, present and future. Chem Rec 2017:17:775-802.

39 Mishchenko T, Mitroshina E, Balalaeva I, et al. An emerging role for nanomaterials in increasing immunogenicity of cancer cell death. Biochim Biophys Acta Rev Cancer 2019;1871:99-108.

40 Krammer B. Vascular effects of photodynamic therapy. Anticancer Res 2001;21:4271-7.

41 Mroz P, Szokalska A, Wu MX, et al. Photodynamic therapy of tumors can lead to development of systemic antigen-specific immune response. PLoS One 2010;5:0015194.
42 Castano AP, Mroz P, Hamblin MR. Photodynamic therapy and antitumour immunity. Nat Rev Cancer 2006;6:535-45.

43 Garg AD, Krysko DV, Verfaillie T, et al. A novel pathway combining calreticulin exposure and ATP secretion in immunogenic cancer cell death. Embo J 2012;31:1062-79.

44 Adkins I, Fucikova J, Garg AD, et al. Physical modalities inducing immunogenic tumor cell death for cancer immunotherapy. Oncoimmunology 2014;3:e968434.

45 Li W, Yang J, Luo L, et al. Targeting photodynamic and photothermal therapy to the endoplasmic reticulum enhances immunogenic cancer cell death. Nat Commun 2019;10:019-11269.

46 Turubanova VD, Balalaeva IV, Mishchenko TA, Catanzaro E, et al. Immunogenic cell death induced by a new photodynamic therapy based on photosens and photodithazine. J Immunother Cancer 2019;7:019-826.

47 Gomes-da-Silva LC, Zhao L, Bezu L, et al. Photodynamic therapy with redaporfin targets the endoplasmic reticulum and Golgi apparatus. Embo J 2018;37:28.

48 Cincotta L, Szeto D, Lampros E, et al. Benzophenothiazine and benzoporphyrin derivative combination phototherapy effectively eradicates large murine sarcomas. Photochem Photobiol 1996;63:229-37.

49 Kessel D, Reiners JJ. Promotion of proapoptotic signals by lysosomal photodamage. Photochem Photobiol 2015;91:931-6.

50 Kessel D, Evans CL. Promotion of proapoptotic signals by lysosomal photodamage: mechanistic aspects and influence of autophagy. Photochem Photobiol 2016;92:620-3.

51 Ibbotson SH. Adverse effects of topical photodynamic therapy. Photodermatol Photoimmunol Photomed 2011;27:116-30.

52 Doix B, Trempolec N, Riant O, et al. Low photosensitizer dose and early radiotherapy enhance antitumor immune response of photodynamic Therapy-Based dendritic cell vaccination. Front Oncol 2019:9

53 Mishchenko TA, Turubanova VD, Mitroshina EV, et al. Effect of novel porphyrazine photosensitizers on normal and tumor brain cells. $J$ Biophotonics 2020;13:17.

54 TA M, EV M, Turubanova VD, et al. Effect of photosensitizers Photosens, Photodithazine and hypericin on glioma Cells and primary neuronal cultures: a comparative analysis. Sovremennye tehnologii v medicine 2019;11:52-63.

55 Shen C, Pandey A, Man SM. Gasdermins deliver a deadly punch to cancer. Cell Res 2020;30:463-4.

56 Wang Q, Wang Y, Ding J, et al. A bioorthogonal system reveals antitumour immune function of pyroptosis. Nature 2020;579:421-6.

57 Galluzzi L, Buqué A, Kepp O, et al. Reply: immunosuppressive cell death in cancer. Nat Rev Immunol 2017:17:8.

58 Kroemer G, Galluzzi L, Kepp O, et al. Immunogenic cell death in cancer therapy. Annu Rev Immunol 2013;31:51-72.

59 Garg AD, Coulie PG, Van den Eynde BJ, et al. Integrating next-generation dendritic cell vaccines into the current cancer immunotherapy landscape. Trends Immunol 2017;38:577-93.

60 Korbelik M, Zhang W, Merchant S. Involvement of damageassociated molecular patterns in tumor response to photodynamic therapy: surface expression of calreticulin and high-mobility group box-1 release. Cancer Immunol Immunother 2011;60:1431-7.

61 Tanaka M, Kataoka H, Yano S, et al. Immunogenic cell death due to a new photodynamic therapy (PDT) with glycoconjugated chlorin (G-chlorin). Oncotarget 2016;7:47242-51.

62 Panaretakis T, Kepp O, Brockmeier U, et al. Mechanisms of preapoptotic calreticulin exposure in immunogenic cell death. Embo J 2009;28:578-90.

63 Grootjans J, Kaser A, Kaufman RJ, et al. The unfolded protein response in immunity and inflammation. Nat Rev Immunol 2016;16:469-84.

64 Garg AD, Kaczmarek A, Krysko O, et al. Er stress-induced inflammation: does it aid or impede disease progression? Trends Mol Med 2012;18:589-98.

65 Panzarini E, Inguscio V, Fimia GM, et al. Rose Bengal acetate photodynamic therapy (RBAc-PDT) induces exposure and release of damage-associated molecular patterns (DAMPs) in human HeLa cells. PLoS One 2014;9:e105778.

66 Garg AD, Krysko DV, Vandenabeele P, et al. Hypericin-Based photodynamic therapy induces surface exposure of damageassociated molecular patterns like Hsp70 and calreticulin. Cancer Immunol Immunother 2012;61:215-21.

67 Bezu L, Sauvat A, Humeau J, et al. elF2 $\alpha$ phosphorylation: A hallmark of immunogenic cell death. Oncoimmunology 2018;7:e1431089.

68 Krysko DV, Ravichandran KS, Vandenabeele P. Macrophages regulate the clearance of living cells by calreticulin. Nat Commun 2018:9:018-6807. 
69 Feng M, Marjon KD, Zhu F, et al. Programmed cell removal by calreticulin in tissue homeostasis and cancer. Nat Commun 2018;9:018-5211.

70 Garg AD, Vandenberk L, Koks C, et al. Dendritic cell vaccines based on immunogenic cell death elicit danger signals and T cell-driven rejection of high-grade glioma. Sci Transl Med 2016;8:328ra27.

71 Trempolec N, Doix B, Degavre C, et al. Photodynamic TherapyBased dendritic cell vaccination suited to treat peritoneal mesothelioma. Cancers 2020;12:545.

72 Mitra S, Giesselman BR, De Jesús-Andino FJ, et al. Tumor response to $\mathrm{MTHPC}$-mediated photodynamic therapy exhibits strong correlation with extracellular release of Hsp70. Lasers Surg Med 2011;43:632-43.

73 Jalili A, Makowski M, Świtaj T, et al. Effective photoimmunotherapy of murine colon carcinoma induced by the combination of photodynamic therapy and dendritic cells. Clin Cancer Res 2004;10:4498-508

74 Korbelik M, Sun J, Cecic I. Photodynamic therapy-induced cell surface expression and release of heat shock proteins: relevance for tumor response. Cancer Res 2005:65:1018-26.

75 Wang $\mathrm{X}$, Ji J, Zhang $\mathrm{H}$, et al. Stimulation of dendritic cells by DAMPs in ALA-PDT treated SCC tumor cells. Oncotarget 2015;6:44688-702.

76 Michaud M, Martins I, Sukkurwala AQ, et al. Autophagy-Dependent anticancer immune responses induced by chemotherapeutic agents in mice. Science 2011;334:1573-7.

77 Garg AD, Dudek AM, Ferreira GB, et al. Ros-Induced autophagy in cancer cells assists in evasion from determinants of immunogenic cell death. Autophagy 2013;9:1292-307.

78 Vanpouille-Box C, Alard A, Aryankalayil MJ, et al. Dna exonuclease TREX1 regulates radiotherapy-induced tumour immunogenicity. Nat Commun 2017;8:15618.

79 Deutsch E, Chargari C, Galluzzi L, et al. Optimising efficacy and reducing toxicity of anticancer radioimmunotherapy. Lancet Oncol 2019;20:e452-63.

80 Pinto A, Mace Y, Drouet F, et al. A new ER-specific photosensitizer unravels 1O2-driven protein oxidation and inhibition of deubiquitinases as a generic mechanism for cancer PDT. Oncogene 2016;35:3976-85.

81 Lépine S, Allegood JC, Edmonds Y, et al. Autophagy induced by deficiency of sphingosine-1-phosphate phosphohydrolase 1 is switched to apoptosis by calpain-mediated autophagy-related gene 5 (Atg5) cleavage. J Biol Chem 2011;286:44380-90.

82 Tatsuno K, Yamazaki T, Hanlon D, et al. Extracorporeal photochemotherapy induces bona fide immunogenic cell death. Cell Death Dis 2019;10:019-1819.

83 Ventura A, Vassall A, Robinson E, et al. Extracorporeal photochemotherapy drives Monocyte-to-Dendritic cell maturation to induce anticancer immunity. Cancer Res 2018;78:4045-58.

84 Coppard C, Hannani D, Humbert M, et al. In vitro PUVA treatment triggers calreticulin exposition and HMGB1 release by dying T lymphocytes in GVHD: new insights in extracorporeal photopheresis. J Clin Apher 2019;34:450-60.

85 Montico B, Nigro A, Casolaro V, et al. Immunogenic apoptosis as a novel tool for anticancer vaccine development. Int $\mathrm{J} \mathrm{Mol} \mathrm{Sci}$ 2018; $19: 594$.

86 Martins I, Wang Y, Michaud M, et al. Molecular mechanisms of ATP secretion during immunogenic cell death. Cell Death Differ 2014;21:79-91.

87 Lamberti MJ, Mentucci FM, Roselli E, et al. Photodynamic modulation of type 1 interferon pathway on melanoma cells promotes dendritic cell activation. Front Immunol 2019;10.

88 Etminan N, Peters C, Lakbir D, et al. Heat-Shock protein 70-dependent dendritic cell activation by 5 -aminolevulinic acid-mediated photodynamic treatment of human glioblastoma spheroids in vitro. Br J Cancer 2011;105:961-9

89 Shams M, Owczarczak B, Manderscheid-Kern P, et al. Development of photodynamic therapy regimens that control primary tumor growth and inhibit secondary disease. Cancer Immunol Immunother 2015:64:287-97.

90 Bae S-M, Kim Y-W, Kwak S-Y, et al. Photodynamic therapygenerated tumor cell lysates with $\mathrm{CpG}$-oligodeoxynucleotide enhance immunotherapy efficacy in human papillomavirus 16 (E6/ E7) immortalized tumor cells. Cancer Sci 2007;98:747-52.

91 Park EK, Bae S-M, Kwak S-Y, et al. Photodynamic therapy with recombinant adenovirus AdmIL-12 enhances anti-tumour therapy efficacy in human papillomavirus 16 (E6/E7) infected tumour model. Immunology 2008;124:461-8.

92 Kleinovink JW, van Driel PB, Snoeks TJ, et al. Combination of photodynamic therapy and specific immunotherapy efficiently eradicates established tumors. Clin Cancer Res 2016;22:1459-68.
93 Josefsen LB, Boyle RW. Unique diagnostic and therapeutic roles of porphyrins and phthalocyanines in photodynamic therapy, imaging and theranostics. Theranostics 2012;2:916-66.

94 Mitsunaga M, Ogawa M, Kosaka N, et al. Cancer cell-selective in vivo near infrared photoimmunotherapy targeting specific membrane molecules. Nat Med 2011;17:1685-91.

95 Ogawa M, Tomita Y, Nakamura Y, et al. Immunogenic cancer cell death selectively induced by near infrared photoimmunotherapy initiates host tumor immunity. Oncotarget 2017;8:10425-36.

96 Lu K, He C, Lin W. A Chlorin-Based nanoscale Metal-Organic framework for photodynamic therapy of colon cancers. J Am Chem Soc 2015;137:7600-3.

97 He C, Duan X, Guo N, et al. Core-Shell nanoscale coordination polymers combine chemotherapy and photodynamic therapy to potentiate checkpoint blockade cancer immunotherapy. Nat Commun 2016;7.

98 Duan X, Chan C, Guo N, et al. Photodynamic therapy mediated by nontoxic Core-Shell nanoparticles synergizes with immune checkpoint blockade to elicit antitumor immunity and antimetastatic effect on breast cancer. J Am Chem Soc 2016;138:16686-95.

$99 \mathrm{Yu}$ X, Gao D, Gao L, et al. Inhibiting metastasis and preventing tumor relapse by triggering host immunity with tumor-targeted photodynamic therapy using Photosensitizer-Loaded functional Nanographenes. ACS Nano 2017;11:10147-58.

100 Gouirand V, Guillaumond F, Vasseur S. Influence of the tumor microenvironment on cancer cells metabolic reprogramming. Front Oncol 2018;8:117.

101 Li S, Meng W, Guan Z, et al. The hypoxia-related signaling pathways of vasculogenic mimicry in tumor treatment. Biomed Pharmacother 2016;80:127-35.

102 Jain RK. Normalizing tumor microenvironment to treat cancer: bench to bedside to biomarkers. J Clin Oncol 2013;31:2205-18.

103 Cheng Y, Cheng H, Jiang C, et al. Perfluorocarbon nanoparticles enhance reactive oxygen levels and tumour growth inhibition in photodynamic therapy. Nat Commun 2015;6:8785.

104 Castro Cl, Briceno JC. Perfluorocarbon-based oxygen carriers: review of products and trials. Artif Organs 2010;34:no-34.

105 Ma Z, Jia X, Bai J, et al. MnO Gatekeeper: An Intelligent and O -Evolving Shell for Preventing Premature Release of High Cargo Payload Core, Overcoming Tumor Hypoxia, and Acidic $\mathrm{H}_{2} \mathrm{O}_{2}$ -Sensitive MRI. Adv Funct Mater 2017;27:1604258.

106 Liang R, Liu L, He H, et al. Oxygen-boosted immunogenic photodynamic therapy with gold nanocages@manganese dioxide to inhibit tumor growth and metastases. Biomaterials 2018;177:149-60.

$107 \mathrm{He} \mathrm{H}$, Liu L, Liang R, et al. Tumor-Targeted nanoplatform for in situ oxygenation-boosted immunogenic phototherapy of colorectal cancer. Acta Biomater 2020;104:188-97.

$108 \mathrm{Xu} \mathrm{T}, \mathrm{Ma}$ Y, Yuan Q, et al. Enhanced ferroptosis by OxygenBoosted phototherapy based on a 2-in-1 nanoplatform of ferrous hemoglobin for tumor synergistic therapy. ACS Nano 2020:14:3414-25

109 Chen Z, Liu L, Liang R, et al. Bioinspired hybrid protein oxygen nanocarrier amplified photodynamic therapy for eliciting anti-tumor immunity and Abscopal effect. ACS Nano 2018;12:8633-45.

110 Raab O. Uber die Wirkung, fluorescirender Stoe auf infusorien. $Z$ Biol 1900;39:524-46.

111 Tappeiner H, Jodlbauer A. Über die Wirkung Der photodynamischen (fluorescierenden) Stoe auf Protozoen und enzyme. Dtsch Arch Klin Med 1904;39:427-87.

112 Tappeiner H, Jodlbauer A. Die Sensibilisierende Wirkung fluorieszierender Substanzer. Gesammte Untersuchungen uber die photodynamische Erscheinung. Vogel, Leipzig: F. C. W, 1907.

113 Figge FHJ, Weiland GS, Manganiello LOJ. Cancer detection and therapy. affinity of neoplastic, embryonic, and traumatized tissues for porphyrins and metalloporphyrins. Exp Biol Med 1948;68:640-1.

114 Dougherty TJ, Kaufman JE, Goldfarb A, et al. Photoradiation therapy for the treatment of malignant tumors. Cancer Res 1978;38:2628-35.

115 Hage R, Ferreira J, Bagnato VS, et al. Pharmacokinetics of Photogem using fluorescence spectroscopy in dimethylhydrazineinduced murine colorectal carcinoma. Int $J$ Photoenergy 2012;2012:1-8.

116 Trindade FZ, Pavarina AC, Ribeiro APD, et al. Toxicity of photodynamic therapy with led associated to Photogem $\AA$ : an in vivo study. Lasers Med Sci 2012;27:403-11.

117 Beneš J, Poučková P, Zeman J, et al. Effects of tandem shock waves combined with photosan and cytostatics on the growth of tumours. Folia Biol 2011;57:255-60.

118 Ormond AB, Freeman HS. Dye sensitizers for photodynamic therapy. Materials 2013;6:817-40. 
119 Taub AF. Photodynamic therapy in dermatology: history and horizons. J Drugs Dermatol 2004;3:S8-25.

120 Fergin P. Photodynamic therapy for psoriasis? Australas J Dermatol 1996;37:87-8.

121 Jain M, Zellweger M, Wagnières G, et al. Photodynamic therapy for the treatment of atherosclerotic plaque: lost in translation? Cardiovasc Ther 2017;35:e12238-5922.

122 Monjo AL-A, Pringle ES, Thornbury M, et al. Photodynamic inactivation of herpes simplex viruses. Viruses 2018;10. doi:10.3390/v10100532. [Epub ahead of print: 29 Sep 2018].

123 Wormald R, Evans J, Smeeth L, et al. Photodynamic therapy for neovascular age-related macular degeneration. Cochrane Database Syst Rev 2005;19. doi:10.1002/14651858.CD002030.pub2

124 Wachowska M, Muchowicz A, Demkow U. Immunological aspects of antitumor photodynamic therapy outcome. Cent Eur J Immunol 2015;40:481-5.

125 Yamamoto N, Homma S, Sery TW, et al. Photodynamic immunopotentiation: in vitro activation of macrophages by treatment of mouse peritoneal cells with haematoporphyrin derivative and light. Eur J Cancer 1991;27:467-71.

126 Agarwal ML, Larkin HE, Zaidi SI, et al. Phospholipase activation triggers apoptosis in photosensitized mouse lymphoma cells. Cancer Res 1993;53:5897-902.

127 Henderson BW, Donovan JM. Release of prostaglandin E2 from cells by photodynamic treatment in vitro. Cancer Res 1989;49:6896-900.

128 Korbelik M. Induction of tumor immunity by photodynamic therapy. J Clin Laser Med Surg 1996;14:329-34.

129 Gollnick SO, Liu X, Owczarczak B, et al. Altered expression of interleukin 6 and interleukin 10 as a result of photodynamic therapy in vivo. Cancer Res 1997:57:3904-9.

130 Nseyo UO, Whalen RK, Duncan MR, et al. Urinary cytokines following photodynamic therapy for bladder cancer. A preliminary report. Urology 1990;36:167-71.

131 Gollnick SO, Vaughan L, Henderson BW. Generation of effective antitumor vaccines using photodynamic therapy. Cancer Res 2002;62:1604-8.

132 Tyurina YY, St Croix CM, Watkins SC, et al. Redox (phospho) lipidomics of signaling in inflammation and programmed cell death. $J$ Leukoc Biol 2019;106:57-81.

133 Demuynck R, Efimova I, Lin A, et al. A 3D cell death assay to quantitatively determine ferroptosis in spheroids. Cells 2020;9. doi:10.3390/cells9030703. [Epub ahead of print: 13 Mar 2020].

134 Mishchenko TA, Balalaeva IV. New insights into anti-cancer treatment: synergetic action of ferroptosis and photodynamic therapy. Trends Cancer.

135 Berger C, Hoffmann K, Vasquez JG, et al. Rapid generation of maturationally synchronized human dendritic cells: contribution to the clinical efficacy of extracorporeal photochemotherapy. Blood 2010;116:4838-47.

$136 \mathrm{Ji} \mathrm{J}$, Fan Z, Zhou F, et al. Improvement of DC vaccine with ALAPDT induced immunogenic apoptotic cells for skin squamous cell carcinoma. Oncotarget 2015;6:17135-46.

137 Cecic I, Parkins CS, Korbelik M. Induction of systemic neutrophil response in mice by photodynamic therapy of solid tumors. Photochem Photobiol 2001;74:712-20.

138 Henderson BW, Gollnick SO, Snyder JW, et al. Choice of oxygenconserving treatment regimen determines the inflammatory response and outcome of photodynamic therapy of tumors. Cancer Res 2004;64:2120-6.

139 Luz AFS, Pucelik B, Pereira MM, et al. Translating phototherapeutic indices from in vitro to in vivo photodynamic therapy with bacteriochlorins. Lasers Surg Med 2018;50:451-9.
140 Lu K, He C, Guo N, et al. Chlorin-Based nanoscale metal-organic framework systemically rejects colorectal cancers via synergistic photodynamic therapy and checkpoint blockade immunotherapy. $J$ Am Chem Soc 2016:138:12502-10.

141 Yu W, He X, Yang Z, et al. Sequentially responsive biomimetic nanoparticles with optimal size in combination with checkpoint blockade for cascade synergetic treatment of breast cancer and lung metastasis. Biomaterials 2019;217:26.

142 Liu D, Chen B, Mo Y, et al. Redox-Activated porphyrin-based liposome Remote-Loaded with indoleamine 2,3-dioxygenase (IDO) inhibitor for synergistic photoimmunotherapy through induction of immunogenic cell death and blockage of IDO pathway. Nano Lett 2019;19:6964-76.

143 Liu R, An Y, Jia W, et al. Macrophage-mimic shape changeable nanomedicine retained in tumor for multimodal therapy of breast cancer. J Control Release 2020;321:589-601.

144 Yang W, Zhang F, Deng H, et al. Smart Nanovesicle-Mediated immunogenic cell death through tumor microenvironment modulation for effective photodynamic immunotherapy. ACS Nano 2020;14:620-31.

145 Xie W, Zhu S, Yang B, et al. The destruction of laser-induced phase-transition nanoparticles triggered by low-intensity ultrasound: an innovative modality to enhance the immunological treatment of ovarian cancer cells. Int J Nanomedicine 2019;14:9377-93.

146 Wang Z, Zhang F, Shao D, et al. Janus Nanobullets combine photodynamic therapy and magnetic hyperthermia to potentiate synergetic anti-metastatic immunotherapy. Adv Sci 2019;6:1901690.

147 Cai Z, Xin F, Wei Z, et al. Photodynamic therapy combined with antihypoxic signaling and $\mathrm{CpG}$ adjuvant as an in situ tumor vaccine based on Metal-Organic framework nanoparticles to boost cancer immunotherapy. Adv Healthc Mater 2020;9:20.

148 Zhang J, Zhang D, Li Q, et al. Task-Specific design of ImmuneAugmented nanoplatform to enable high-efficiency tumor immunotherapy. ACS Appl Mater Interfaces 2019;11:42904-16.

$149 \mathrm{Liu} \mathrm{H}, \mathrm{Hu}$ Y, Sun Y, et al. Co-Delivery of bee venom melittin and a photosensitizer with an Organic-Inorganic hybrid nanocarrier for photodynamic therapy and immunotherapy. ACS Nano 2019;13:12638-52.

150 Yan S, Zeng X, Tang Yong'an, Tang Y, et al. Activating antitumor immunity and antimetastatic effect through PolydopamineEncapsulated core-shell upconversion nanoparticles. Adv Mater 2019;31:1905825.

151 Huang H, Banerjee S, Qiu K, et al. Targeted photoredox catalysis in cancer cells. Nat Chem 2019;11:1041-8.

152 Huang Z, Wei G, Zeng Z, et al. Enhanced cancer therapy through synergetic photodynamic/immune checkpoint blockade mediated by a liposomal conjugate comprised of porphyrin and IDO inhibitor. Theranostics 2019;9:5542-57.

153 Ma B, Sheng J, Wang P, et al. Combinational phototherapy and hypoxia-activated chemotherapy favoring antitumor immune responses. Int J Nanomedicine 2019;14:4541-58.

154 Feng B, Hou B, Xu Z, et al. Self-Amplified drug delivery with lightinducible Nanocargoes to enhance cancer immunotherapy. Adv Mater 2019;31:1902960.

155 Ni K, Aung T, Li S, et al. Nanoscale metal-organic framework mediates radical therapy to enhance cancer immunotherapy. Chem 2019;5:1892-913.

156 Deng H, Zhou Z, Yang W, et al. Endoplasmic reticulum targeting to amplify immunogenic cell death for cancer immunotherapy. Nano Lett 2020;20:1928-33. 


\section{Correction: Targeting immunogenic cancer cell death by photodynamic therapy: past, present and future}

Alzeibak R, Mishchenko TA, Shilyagina NY, et al. Targeting immunogenic cancer cell death by photodynamic therapy: past, present and future. J ImmunoTher Cancer 2021;9:e001926. doi: 10.1136/jitc-2020-001926

This article has been corrected since it first published. The provenance and peer review statement has been added.

Open access This is an open access article distributed in accordance with the Creative Commons Attribution Non Commercial (CC BY-NC 4.0) license, which permits others to distribute, remix, adapt, build upon this work non-commercially, and license their derivative works on different terms, provided the original work is properly cited, appropriate credit is given, any changes made indicated, and the use is non-commercial. See http://creativecommons.org/licenses/by-nc/4.0/.

(C) Author(s) (or their employer(s)) 2021. Re-use permitted under CC BY-NC. No commercial re-use. See rights and permissions. Published by BMJ.

J Immunother Cancer 2021;9:e001926corr1 . doi:10.1136/jitc-2020-001926corr1

D) Check for updates 